\title{
Quantifying seasonal air-sea gas exchange processes using noble gas time-series: A design experiment
}

\author{
by Rachel H. R. Stanley ${ }^{1,2}$, William J. Jenkins ${ }^{1}$ and Scott C. Doney ${ }^{1}$
}

\begin{abstract}
A multi-year time-series of measurements of five noble gases ( $\mathrm{He}, \mathrm{Ne}, \mathrm{Ar}, \mathrm{Kr}$, and $\mathrm{Xe}$ ) at a subtropical ocean location may allow quantification of air-sea gas exchange parameters with tighter constraints than is currently available by other methods. We have demonstrated this using a one-dimensional upper ocean model forced by 6-hourly NCEP reanalysis winds and heat flux for the Sargasso Sea near Bermuda. We performed ensemble model runs to characterize the response of the modeled noble gas saturation anomalies to a range of air-sea gas exchange parameters. We then used inverse calculations to quantify the sensitivity of the parameters to hypothetical observations. These calculations show that with currently achievable measurement accuracies, noble gas concentrations in the Sargasso Sea could be used to constrain the magnitude of equilibrium gas exchange to $\pm 11 \%$, the magnitude of the total air injection flux to $\pm 14 \%$, and the magnitude of net photosynthetic oxygen production to $\pm 1.5 \mathrm{~mol} \mathrm{O}_{2} \mathrm{~m}^{-2} \mathrm{y}^{-1}$. Additionally, we can use noble gases to quantify the relative contributions of bubbles that are partially dissolved to bubbles that are completely dissolved. These constraints are based on idealized assumptions and may not fully account for some of the uncertainties in the meteorological data, in lateral transport processes, and in the solubilities of the noble gases. As a limited demonstration, we applied this approach to a time series of $\mathrm{He}, \mathrm{Ne}, \mathrm{Ar}$, and $\mathrm{O}_{2}$ measurements from the Sargasso Sea from 1985 to 1988 (data from Spitzer, 1989). Due to the limited number of gases measured and the lower accuracy of those measurements, the constraints in this example application are weaker than could be achieved with current capabilities.
\end{abstract}

\section{Introduction}

Air-sea gas exchange is a crucial component of the biogeochemical cycles of many important gases, including $\mathrm{O}_{2}$ and $\mathrm{CO}_{2}$. However, existing air-sea gas exchange parameterizations have uncertainties of $20 \%$ to $50 \%$ (Liss and Merlivat, 1986; Wanninkhof, 1992; Wanninkhof and McGillis, 1999; Nightingale et al., 2000). Eddy correlation techniques provide estimates based on hourly time scales (Wanninkhof and McGillis, 1999). Radon deficit calculations (Peng et al., 1979) and deliberate dual release experiments (Watson et $a l ., 1991)$ allow prediction of gas transfer functions for time scales of several days to two weeks. At the opposite end of the spectrum, gas transfer functions determined from natural

1. Department of Marine Chemistry and Geochemistry, Woods Hole Oceanographic Institution, Woods Hole, Massachusetts, 02543, U.S.A.

2. Corresponding author.email: rstanley@whoi.edu 
${ }^{14} \mathrm{C}$ balance or bomb ${ }^{14} \mathrm{C}$ considerations (Broecker and Peng, 1974; Wanninkhof and McGillis, 1999) are based on decadal or longer time scales. The techniques that determine air-sea gas exchange parameters from direct empirical data, such as purposeful release experiments, are time-consuming and expensive and have only been applied in limited areas of the ocean. Additionally, few of these methods average gas exchange over time-scales of weeks to months, and yet it is those time scales that most affect nutrient cycling and biological production.

A monthly time-series of noble gas measurements may help constrain air-sea gas exchange parameterizations on monthly time-scales and regional spatial scales. Noble gases are an ideal tool for such an investigation because they are chemically and biologically inert, and therefore respond only to physical processes such as air-sea gas exchange, mixing, transport, etc. Seasonal warming and air injection due to large wind events drive noble gases out of equilibrium while diffusive gas exchange works to restore equilibrium. The five stable noble gases, helium (He), neon (Ne), argon (Ar), krypton (Kr), and xenon (Xe), have a wide range of physical properties. The solubilities of the gases differ by a factor of ten and the diffusivities by a factor of five (Wood and Caputi, 1966; Weiss, 1970, 1971; Weiss and Kyser, 1978; Jähne et al., 1987; Hamme and Emerson, 2004). In addition, the solubilities of $\mathrm{Kr}$ and $\mathrm{Xe}$ are strongly dependent on temperature, whereas the solubilities of $\mathrm{He}$ and $\mathrm{Ne}$ are weakly dependent on temperature. This range in properties causes the gases to respond differently to physical forcing and thus allows quantification of a variety of physical processes.

To quantify these physical processes, we must combine noble gas measurements with a numerical model that simulates the noble gas concentrations in a time-evolving environment. The primary objective of the model is to provide a first order, time-varying description of the key factors that influence noble gas distributions such as the vertical distribution of temperature, salinity and mixing in the water column. This modeling is easier for two reasons if we study the noble gases near Bermuda in the Sargasso Sea at the Bermuda Atlantic Time-Series Study (BATS) site $\left(31^{\circ} 40^{\prime} \mathrm{N}, 64^{\circ} 10^{\prime} \mathrm{W}\right)$. First, a wealth of hydrographic data exists from the BATS site and nearby Station S (32 $\left.10^{\prime} \mathrm{N}, 64^{\circ} 30^{\prime} \mathrm{W}\right)$ that can be used to constrain the physical parameters in the model. A biweekly time-series of temperature, salinity, oxygen, and other measurements exists at Station S from 1954 (Schroeder and Stommel, 1969) with a similar monthly time-series at BATS from 1988 (Michaels and Knap, 1996). Second, a one-dimensional vertical model can be used for the gases with fewer problems at this site than at many others. Thermal forcing is one of the largest determinants of gas saturation state, and at the BATS site, the large-scale circulation nearly parallels the zero contour of net heat flux (Jenkins and Doney, 2003). Thus the temperature history of the upper water column with respect to thermal forcing does not vary greatly laterally, suggesting that a one-dimensional model may produce reasonable values for noble gas distributions.

In this paper, we present a design experiment: given noble gas measurements at currently achievable measurement accuracy, how well can we quantify air-sea gas 
exchange processes? First, we describe the model and method used to constrain air-sea gas exchange parameters from noble gas measurements (Section 2). Second, we present the choice of physical parameters used in the model and show that the model successfully mimics temperature and salinity data from the Sargasso Sea (Section 3). Third, we present a sensitivity study quantifying how well noble gas measurements can constrain a variety of air-sea gas exchange parameters (Section 4). Finally, as a limited demonstration we apply this method to a three-year time-series of $\mathrm{He}, \mathrm{Ne}, \mathrm{Ar}$, and $\mathrm{O}_{2}$ measurements collected at Station S from 1985-1988 (Spitzer, 1989) and determine preliminary values for air-sea gas exchange parameters in a subtropical oligotrophic gyre (Section 5).

\section{Methods}

\section{a. Description of the one-dimensional vertical upper ocean model: Physical parameters}

We used a one-dimensional, vertical, modified Price-Weller-Pinkel (PWP) model (Price et al., 1986). The model previously had been extended to include $\mathrm{He}, \mathrm{Ne}, \mathrm{Ar}$, and $\mathrm{O}_{2}$ (Spitzer and Jenkins, 1989), and here we extended it further to include $\mathrm{Kr}$ and Xe. Moreover, whereas Spitzer and Jenkins (1989) used climatological data to force their model, we used six-hourly National Centers for Environmental Prediction (NCEP) reanalysis heat fluxes, wind stress, precipitation, etc. (Kistler et al., 2001), interpolated for the BATS site. The annually averaged net heat flux obtained from the NCEP reanalysis for this location is negative (net cooling) suggesting that lateral advection balances the heat budget over decadal, or possibly longer, time scales. Thus a positive heat flux, calculated by balancing the sum of the NCEP heat flux terms to zero (on order 30 to $50 \mathrm{~W} \mathrm{~m}^{-2}$ ), is added to the model to compensate for the NCEP extraction of heat and to simulate the effects of lateral advection.

In addition, in the model there is an effective heat convergence associated with Ekman pumping. We computed the Ekman pumping from the four day low-pass filtered local wind stress curl derived from the NCEP reanalysis data. The Ekman pumping-induced vertical velocity is tapered to zero at the bottom of the model domain, in approximate concordance with the Sverdrup relation. The vertical heat flux convergence associated with this flux results in a net heat gain in the model. To prevent the model from warming, a heat flux of order $5 \mathrm{~W} \mathrm{~m}^{-2}$ is removed from the water column. The exact magnitude of this Ekman heat convergence compensation term $(E \mathrm{~km})$ is difficult to calculate explicitly because it depends on the simulated vertical temperature profile in conjunction with the vertical velocity profile, and to a lesser extent on vertical mixing. It thus was treated as a model parameter that was adjusted for long term heat balance. Furthermore, varying Ekm has the effect of partially compensating for errors in the NCEP heat fluxes. We evaluated physical model performance as a function of the magnitude of $E \mathrm{~km}$, the depth range over which the total heat flux offset (sum of the Ekman compensation and NCEP balance terms) is distributed $(Z)$, the time scale over which the heat budget is forced to balance, and the background vertical diffusivity $\left(K_{z}\right)$. 
We determined the optimum values for these tunable physical parameters from ensemble runs $(n \sim 100)$ calculated using an initially wide range of physical parameter values: $10^{-5}<K_{z}<10^{-4} \mathrm{~m}^{2} \mathrm{~s}^{-1}, 1<E k m<15 \mathrm{~W} \mathrm{~m}^{-2}$, and $10<Z<400 \mathrm{~m}$. We quantitatively compared the output of these runs to BATS and Station S data through the use of a cost function based on the sum of the weighted root mean square difference between model and observations. Quantities included in the cost function were the winter mixed layer depth, summer mixed layer temperature, winter mixed layer temperature, summer mixed layer salinity, average temperature in the top $600 \mathrm{~m}$, and average salinity in the top $600 \mathrm{~m}$. The mixed layer depth contribution to the cost function was weighted by $25 \mathrm{~m}$, the temperatures by $0.5^{\circ} \mathrm{C}$, and the salinities by $0.1 \mathrm{psu}$. As a comparision, we also calculated a second cost function based on the root mean square difference between model and observed temperature and salinity at depths ranging from the surface to $150 \mathrm{~m}$. In both cases, a narrower range of physical parameters was then chosen near the optimum and another ensemble run was performed. The process was repeated until the cost functions displayed no significant difference between the optimal values of physical parameters.

The net water flux was determined by the difference between the NCEP precipitation flux and the evaporation, calculated by converting the latent heat flux from $\mathrm{W} \mathrm{m}^{-2}$ to $\mathrm{kg} \mathrm{m}^{2} \mathrm{~s}^{-1}$. The net evaporation minus precipitation is about $65 \mathrm{~cm} \mathrm{y}^{-1}$ so an offset is applied to balance the freshwater flux over the period, assuming that this is typically achieved in the ocean by a lateral freshwater flux divergence. The optimal value for this offset was determined from the BATS salinity data. The model and the gas distributions are not very sensitive to changes in salinity at this location and thus are not sensitive to the value of this offset.

For the sensitivity study (Section 4), the model was spun up from 1992-1999 with initial conditions of temperature and salinity profiles from BATS data and all gas concentrations at equilibrium. We used the cost function/ensemble run method described above in conjunction with the BATS and Station S data from 1992 to 2002 in order to calculate the optimal physical parameters for this time period. Then simulated noble gas concentrations from 1999-2002 were used to quantitatively investigate potential constraints on air-sea gas exchange parameters.

For the example application (Section 5), the model was spun up from 1978 to 1985 and then simulations from 1985 to 1988 were used in conjunction with time-series data to determine the air-sea gas exchange parameters. To determine the optimal physical parameters, we used an inverse analysis with BATS temperature and noble gas data. To determine a reasonable range of physical parameters, we used the cost function/ensemble run method described above. This range of physical parameters allowed us to calculate the additional uncertainty in the air-sea gas exchange parameters due to uncertainty in the physical parameters. The optimal physical parameters for the 1992-2002 decade differed from those for the 1978-1988 time period, probably because of differences in lateral processes (such as eddies) that are not resolved in the model. 


\section{b. Description of the model: Gas exchange parameters}

Gas exchange processes are modeled according to standard literature parameterizations with adjustment permitted through the use of tunable model parameters. The total flux of a gas, $F_{T O T}$, is the sum of the flux due to diffusive gas exchange, $F_{G E}$, and the flux due to air injection, $F_{A I}$ :

$$
F_{T O T}=F_{G E}+F_{A I}
$$

The diffusive gas exchange flux, $F_{G E}\left(\mathrm{~mol} \mathrm{~m}^{-2} \mathrm{~s}^{-1}\right)$ is given by

$$
F_{G E}=\gamma_{G} \cdot 7.9 \times 10^{-8}\left(\frac{S c}{660}\right)^{-0.5} u_{10}^{n}\left(C_{i, e q}-C_{i, w}\right)
$$

where $\gamma_{G}$ is a tunable model parameter of order 1 controlling the magnitude of the flux, the coefficient is the constant used by Wanninkhof and McGillis (1999) converted to units of $\mathrm{m} \mathrm{s}^{-1}, S c$ is the Schmidt number (ratio of the kinematic viscosity to the molecular diffusivity of the gas of interest), $u_{10}$ is the wind speed $\left(\mathrm{m} \mathrm{s}^{-1}\right)$ at $10 \mathrm{~m}$ height above sea-surface, $n$ is the exponent controlling the wind-speed dependency of the flux, and $C_{i, w}$ and $C_{i, e q}$ are the concentrations of gas $i$ in the water and at equilibrium, respectively. A cubic wind speed dependency $(n=3)$, as proposed by Wanninkhof and McGillis (1999), is used in most model runs. In the few runs with a quadratic wind speed dependency $(n=2)$, the value of the coefficient changes to $8.6 \times 10^{-7} \mathrm{~m} \mathrm{~s}^{-1}$, in order to scale the total gas flux to the global average ${ }^{14} \mathrm{C}$ exchange rate (for details see Wanninkhof, 1992).

In the model, the flux due to air injection, $F_{A I}$, has contributions from two types of bubbles. Some bubbles are completely trapped, i.e. completely dissolved after injection, and therefore inject air of atmospheric abundances into the water column. Other bubbles only partially dissolve before rising to the surface, in which case the injected gases are fractionated as a function of diffusivity and solubility (Fuchs et al., 1987; Jenkins, 1988; Keeling, 1993; Woolf, 1993). Thus the total air injection flux, $F_{A I}$, is equal to

$$
F_{A I}=F_{C}+F_{P}
$$

where $F_{C}$ refers to the flux from bubbles that are completely trapped and $F_{P}$ refers to the flux from bubbles that are only partially dissolved.

The flux due to completely trapped bubbles is dependent on the partial pressure of the gas in the atmosphere and the volume entrainment rate of the air entrained. This volume entrainment rate is given by a combination of the whitecap coverage formulation of Monahan and Torgersen (1990) with the air entrainment velocity estimate of Keeling (1993):

$$
F_{C}=\gamma_{A c} \cdot A_{c} \cdot 2 \times 10^{-6}\left(u_{10}-2.27\right)^{3} v_{a} \frac{P_{i, a}}{R T}
$$


where $\gamma_{A c}$ is a tunable model parameter of order 1 that scales the magnitude of the complete trapping flux, $A_{c}$ is a constant coefficient equal to $1.4 \times 10^{-3}, v_{a}$ is the air entrainment velocity $\left(0.01 \mathrm{~m} \mathrm{~s}^{-1}\right), R$ is the gas constant $\left(8.31 \mathrm{~J} \mathrm{~mol}^{-1} \mathrm{~K}^{-1}\right), T$ is the temperature $(\mathrm{K})$, and $P_{i, a}$ is the partial pressure of gas $i$ in the atmosphere $(\mathrm{Pa})$. We calculated the coefficient $A_{c}$ by performing ensemble runs $(n \sim 100)$ and then using a cost function to determine the value of $A_{c}$ that allowed the best match to $\mathrm{He}, \mathrm{Ne}$, and $\mathrm{Ar}$ data from the Sargasso Sea. Eq. 4 is valid for $u_{10} \geq 2.27 \mathrm{~m} \mathrm{~s}^{-1}$. At $u_{10}<2.27 \mathrm{~m} \mathrm{~s}^{-1}, F_{C}$ is set to 0 .

The partial bubble trapping flux depends upon the volume entrainment rate, the solubility and diffusivity of the gas, and the difference between the partial pressure of the gas in the bubble and in the water :

$$
F_{P}=\gamma_{A p} \cdot A_{p} \cdot 2 \times 10^{-6}\left(u_{10}-2.27\right)^{3} v_{a} \alpha_{i}^{a} D_{i}^{b} \frac{\left(P_{i, b}-P_{i, w}\right)}{R T}
$$

where $\gamma_{A p}$ is a tunable model parameter of order 1 that scales the magnitude of the partial trapping flux, $A_{p}$ is a constant coefficient equal to $2 \times 10^{5}$, $\alpha$ is the Bunsen solubility coefficient of gas $i, D$ is the diffusivity $\left(\mathrm{m}^{2} \mathrm{~s}^{-1}\right)$ of gas $i, a$ and $b$ are exponents controlling the power dependency of $\alpha$ and $D$ respectively, and $P_{i, b}$ and $P_{i, w}$ are the partial pressures of the gas in the bubble and in the water $(\mathrm{Pa})$. We calculated the coefficient $A_{p}$ by performing ensemble runs $(n \sim 100)$ and then using a cost function to determine the value of $A_{p}$ that allowed the best match to existing $\mathrm{He}, \mathrm{Ne}$, and Ar data from the Sargasso Sea. The power dependency of $\alpha$ and $D$ can be determined theoretically depending on whether the bubbles are believed to be clean $(a=1, b=1 / 2)$ or dirty $(a=1, b=2 / 3)$ (Levich, 1962) or can be determined by modeling studies of characteristic bubble populations $(a=0.7, b=0.35)$ (Keeling, 1993). In this study, we examined the sensitivity of the results to the choice of $a$ and $b$. Unless noted otherwise, we will report results for $a=1, b=2 / 3$. Eq. 5 is valid only for $u_{10} \geq 2.27 \mathrm{~m} \mathrm{~s}^{-1}$. At $u_{10}<2.27 \mathrm{~m} \mathrm{~s}^{-1}, F_{P}$ is set to 0 . Eq. 5 is similar to the partial trapping flux equation used by Keeling (1993) when appropriate scaling factors and units are used.

The partial pressure of the gas in the bubble, $P_{i, b}$, depends on the size and depth distribution of the bubbles and thus is a complicated problem of bubble dynamics. Here, however, $P_{i, b}$ is simply approximated by:

$$
P_{i, b}=X_{i}\left(P_{\mathrm{atm}}+\rho g h_{b u b}\right)
$$

where $X_{i}$ is the mole fraction of gas $i$ in dry air, $P_{\text {atm }}$ is the atmospheric pressure of dry air $(\mathrm{Pa}), \rho$ is the density of water $\left(\mathrm{kg} \mathrm{m}^{-3}\right), g$ is the gravitational acceleration $\left(9.81 \mathrm{~m} \mathrm{~s}^{-1}\right)$ and $h_{b u b}(\mathrm{~m})$ is the average dissolution depth for the bubbles. This expression takes into account the hydrostatic pressure felt by the bubble but neglects the effects of surface tension on the bubble. The depth $h_{\text {bub }}$, used for the hydrostatic pressure calculation, is approximated by:

$$
h_{b u b}=\frac{1}{2}\left(0.3 u_{10}-1.1\right)
$$


which is the bubble cloud residence depth/wind speed relationship of Graham et al. (2004), multiplied by a bubble depth scaling factor of $1 / 2$ to take into account that the bubbles partially dissolve along their entire downward and upward transect rather than simply at their residence depth. The results were not sensitive to the choice of bubble depth scaling factor since a decrease in the scaling factor could be compensated for by an increase in $\gamma_{\text {Ap }}$. Eq. 7 is valid only for $u_{10} \geq 0.37 \mathrm{~m} \mathrm{~s}^{-1}$. At $u_{10}<0.37 \mathrm{~m} \mathrm{~s}^{-1}, h_{\text {bub }}$ is set to 0 .

Both the diffusive gas exchange flux and the air injection flux parameterizations (Eq. 2 and Eq. 5) require knowledge of the solubilities of the noble gases. These solubilities were determined by Weiss in the 1970s (Weiss, 1970, 1971; Weiss and Kyser, 1978). More recently, the solubilities of $\mathrm{Ne}$ and Ar were redetermined by Hamme and Emerson (2004), with these newer results differing from those of Weiss by $1 \%$ for $\mathrm{Ne}$ and $0.4 \%$ for Ar. We performed most of the calculations with the $\mathrm{Ne}$ and $\mathrm{Ar}$ solubilities of Hamme and Emerson. We assumed that the difference in the Ne solubilities between Weiss and Hamme and Emerson was due to a systematic difference in technique. We thus scaled the Weiss solubility values for He (which was not determined by Hamme and Emerson) with the same correction factor that was needed to make the Weiss Ne solubility equal to the Hamme and Emerson Ne solubility. This correction factor, which depends on temperature, ranges from $0.5 \%$ at $18^{\circ} \mathrm{C}$ to $1.5 \%$ at $29^{\circ} \mathrm{C}$. We performed some calculations with the Weiss solubilities in order to assess the effect of different solubility functions. Additionally, we propagated the uncertainty in solubility determination, when appropriate, throughout all the calculations.

Biological production is incorporated through the use of an idealized oxygen production and consumption profile. In the upper $100 \mathrm{~m}$, the oxygen productivity profile, Prod, is represented by a sine curve according to

$$
\operatorname{Prod} \propto \sin \left(\frac{\pi z}{100}\right) \text { for } z<100 \mathrm{~m}
$$

where $z$ is depth (m). Below $100 \mathrm{~m}$, oxygen is consumed exponentially:

$$
\text { Prod } \propto \exp \left(\frac{-(z-100)}{z^{*}}\right) \text { for } z>100 \mathrm{~m}
$$

where $z^{*}$ is a scaling depth of $295 \mathrm{~m}$ that was chosen based on tritium-helium dating (Jenkins, 1980). Since oxygen production by photosynthesis above $100 \mathrm{~m}$ should approximately balance oxygen consumption from remineralization below $100 \mathrm{~m}$, the integrated production above $100 \mathrm{~m}$ was scaled to balance the integrated production below $100 \mathrm{~m}$. The total oxygen production and consumption, $P_{T O T}$, is then scaled by tunable model parameter $\gamma_{P}$ and seasonally modulated with maximum production in early spring (Musgrave et al., 1988; Spitzer and Jenkins, 1989), according to

$$
P_{\text {TOT }}=\gamma_{P} \cdot \operatorname{Prod} \cdot\left[1+\sin \left(2 \pi\left(t-t_{o}\right)\right)\right]
$$


Table 1. Reference case values for the tunable gas exchange model parameters chosen either according to literature values $\left(\gamma_{G}, \gamma_{P}\right)$ or to best match previous observations $\left(\gamma_{A c}, \gamma_{A p}\right)$. All of the parameters are unitless except for the oxygen production parameter $\gamma_{P}$.

Model

parameter

Description

Reference value

$\gamma_{G}$
$\gamma_{A c}$
$\gamma_{A p}$
$\gamma_{P}$

Magnitude of diffusive gas exchange

Magnitude of complete trapping component of air injection

Magnitude of partial trapping component of air injection

Magnitude of net biological production

1
1
1
$5 \mathrm{~mol} \mathrm{O}_{2} \mathrm{~m}^{-2} \mathrm{y}^{-1}$

where $t$ is the model time and $t_{o}$ is 1995 (a year in the middle of the time-series). This is an idealized approach to biological productivity and at the moment is not intended to give new information about biological productivity at the BATS site. Rather it simply illustrates that $\mathrm{O}_{2}$ and Ar measurements can be used to constrain biological productivity. Future work will likely use better data assimilation techniques for oxygen and argon in order to estimate useful values of biological production at the BATS site.

\section{c. Linearization and inverse technique}

The equations above mathematically describe the effect of diffusive gas exchange and air injection on the signatures of the noble gases. Qualitatively, the equations illustrate that there are three types of forcing for the noble gases: thermal forcing which changes the saturation state of the gas, diffusive gas exchange, and air injection. For insoluble gases such as $\mathrm{He}$ and $\mathrm{Ne}$, the diffusive gas exchange flux balances the air injection flux, making separation of the terms difficult. For soluble gases such as $\mathrm{Kr}$ and $\mathrm{Xe}$, the air injection flux is relatively less important. Thus thermal heating (which is directly observed) causes a diffusive gas exchange flux, which can then be calculated from mass budgets. We then used this estimated diffusive gas exchange flux and the $\mathrm{He}$ and Ne results to quantify the air injection fluxes. In practice, we actually determined the diffusive and air injection fluxes simultaneously using all five noble gases, as described below.

The four tunable geochemical model parameters in the above equations are gas exchange magnitude $\gamma_{G}$, complete bubble trapping magnitude $\gamma_{A c}$, partial bubble trapping magnitude $\gamma_{A p}$, and biological production magnitude $\gamma_{P}$. In order to quantify these factors, we first constructed a reference case by running the model using the most probable values of all model parameters (Table 1). For $\gamma_{G}$ and $\gamma_{P}$, literature values were used to assign the reference case. For $\gamma_{A c}$ and $\gamma_{A p}$, reference values of 1 were chosen since the coefficients $A_{c}$ and $A_{p}$ had been calculated to best match observations.

Second, we ran the model with a range of values for a given model parameter, holding all other model parameters constant at the reference values, in order to linearize the response of an observational metric to a given model parameter. The observational metrics are measurable quantities, such as the surface saturation anomaly of a noble gas. This linearization ultimately allowed us to estimate how well noble gas measurements, at 
current measurement capabilities, can constrain air-sea gas exchange parameters. The linearizations are robust to data noise and physical model error, and they provide direct interpretation of parameter impact on observational metrics and error propagation. The sensitivity study shows that the approximation of a linear response is appropriate.

As an initial step, we used the linearizations in a partial derivative method to determine which observational metrics offer the best constraints on a given model parameter. This approach assumes all other model parameters are known with zero error. All uncertainties in this paper refer to $1 \sigma$ values. The estimated uncertainty in the model parameter, $\sigma_{\text {param }}$, which is essentially the constraint on the model parameter, can be calculated from the following equation:

$$
\frac{\sigma_{\text {metric }}}{\sigma_{\text {param }}}=\frac{\Delta \text { Observational Metric }}{\Delta \text { Model Parameter }}=\text { slope }
$$

where $\sigma_{\text {metric }}$ is the estimated uncertainty in the observational metrics achievable with present measurement capabilities and slope refers to the slope calculated from the linearization. Laboratory experiments indicate that it is possible to achieve at least $0.1 \%$ measurement uncertainty on measurements of $\mathrm{He}, \mathrm{Ne}$, and $\mathrm{Ar}$ and at least $0.2 \%$ measurement uncertainty on measurements of $\mathrm{Kr}$ and Xe using peak height manometry on a quadrupole mass spectrometer. Such uncertainties depend on adequate purification and separation of gases to eliminate matrix effects, and highly reproducible experimental procedures achieved by precise computer control of all processing. There will be additional error due to sampling and gas extraction. However, systematic biases can be assessed by careful experimentation, and random errors can be overcome by over-sampling the water column (e.g., multiple samples within the mixed layer).

The situation is more complicated than the partial derivative method suggests because we do not know, a priori, the values for any of the model parameters and because the metrics depend on more than one parameter. In order to take into account this complexity, we also calculated the parameter constraints using a full inverse method that utilizes multiple observational metrics. For the full inverse method, we used simulated "data" of the distributions of the five noble gases from a model run with reference model parameters. Then we used singular value decomposition (SVD) and the linearizations to simultaneously determine all of the model parameters from the "data" weighted by the currently achievable measurement uncertainty of the observational metrics. The uncertainties determined from the SVD calculations give us the potential constraints on the model parameters. In the future, when we have an actual dataset of all five noble gases, we will explore using nonlinear optimization techniques rather than the SVD.

Additionally, we calculated linearizations using different sets of physical parameters (see Section 3 for description of the sets of physical parameters) and thus determined the uncertainty produced by ambiguity in the one-dimensional model physics. We added in quadrature the uncertainty due to the noble gas measurements as determined from the SVD 

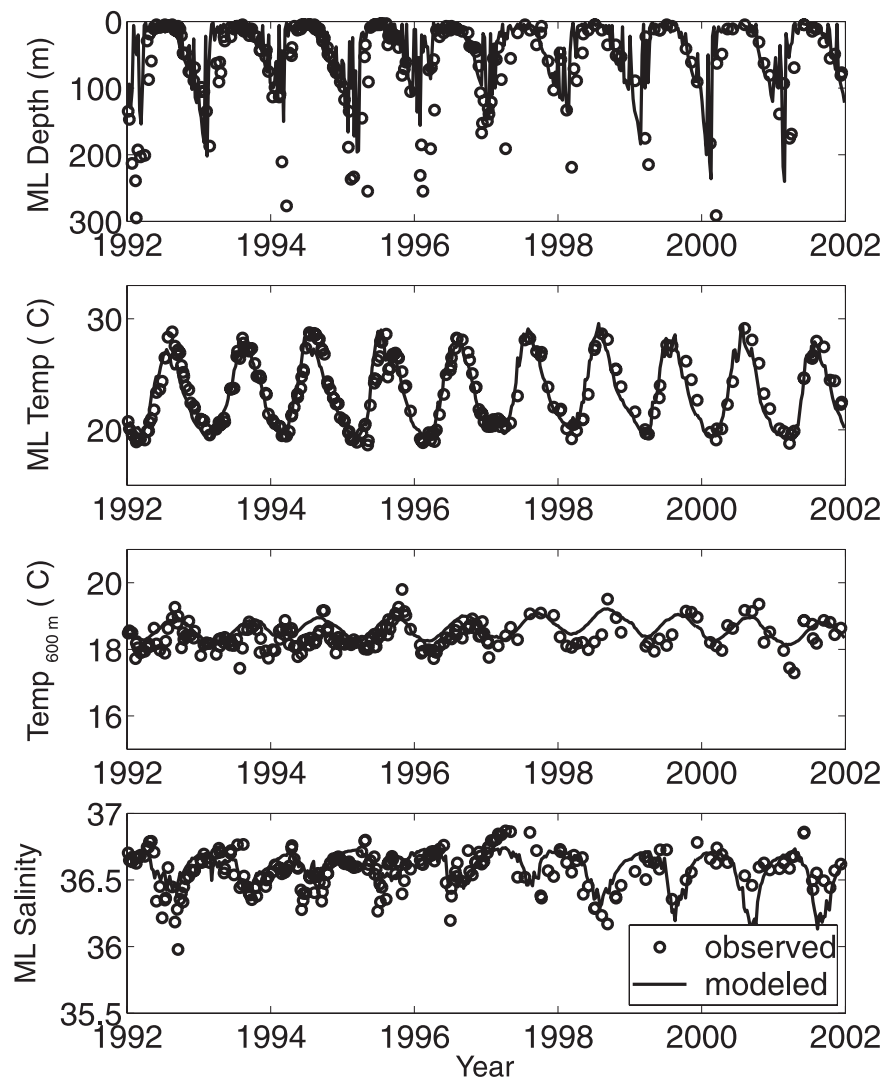

Figure 1. Comparison of model predictions (-) with BATS/Station S data (o) for mixed layer depth, mixed layer temperature, average temperature in the top $600 \mathrm{~m}$, and mixed layer salinity. Mixed layer depth was determined from BATS/Station $\mathrm{S}$ data using a potential density criterion of $\Delta 0.1$ $\mathrm{kg} \mathrm{m}^{-3}$. Physical parameters used in this reference simulation are background vertical diffusion $K_{z}=6 \times 10^{-5} \mathrm{~m}^{2} \mathrm{~s}^{-1}$, Ekman heat convergence $E k m=6.5 \mathrm{~W} \mathrm{~m}^{-2}$, and depth to which heat offset is added $Z=100 \mathrm{~m}$.

and the uncertainties due to model physics to determine final constraints on the model parameters.

\section{Choice of physical parameters}

The physical model is able to mimic reasonably well the mixed layer depth, temperature, salinity, and average temperature in the top $600 \mathrm{~m}$ (approximately proportional to total heat content) for a ten-year period when the appropriate physical parameters are chosen (Fig. 1). The root mean square deviations between model and data are $70 \mathrm{~m}$ for mixed layer depth, $1.2^{\circ} \mathrm{C}$ for mixed layer temperature, $0.13 \mathrm{psu}$ for mixed layer salinity, and $0.4^{\circ} \mathrm{C}$ for average temperature in the top $600 \mathrm{~m}$. The winter mixed layer depths predicted by the model have 
the largest root mean square deviation from the data relative to the weights assigned in the cost function. This may be because the mixed layer depth is sensitive to convection of relatively homogeneous mode waters, and thus small year-to-year variations in lateral heat transport, mesoscale eddies, and errors in heat fluxes can lead to large variations in winter mixed layer depth (Doney, 1996). No long-term drift is apparent in the optimized model, even when the model is run for forty-five years. The model-data agreement suggests that the model is an adequate description for the seasonal physical evolution used for the noble gases.

The best set of physical parameters for the time period 1992 to 2002 consists of $K_{z}=$ $6 \times 10^{-5} \mathrm{~m}^{2} \mathrm{~s}^{-1}, Z=100 \mathrm{~m}$, and $E \mathrm{~km}=6.5 \mathrm{~W} \mathrm{~m}^{-2}$. However, we found that the parameters work in concert, with various sets of physical parameters yielding similar cost functions. If $K z$ ranged from $2 \times 10^{-5} \mathrm{~m}^{2} \mathrm{~s}^{-1}$ to $8 \times 10^{-5} \mathrm{~m}^{2} \mathrm{~s}^{-1}$, we could still achieve reasonably low cost functions. For model runs with $K z$ outside this range, the cost functions increased significantly and the model results could no longer match the seasonal temperature cycle observed at BATS. We thus carried out the modeling and determination of air-gas exchange parameters with three sets of physical parameters: (1) the optimal set, as listed above (all results in figures and tables are for this case); (2) $K z=8 \times 10^{-5} \mathrm{~m}^{2} \mathrm{~s}^{-1}, E \mathrm{~km}=$ $5 \mathrm{~W} \mathrm{~m}^{-2}, Z=100 \mathrm{~m}$; and (3) $K z=2 \times 10^{-5} \mathrm{~m}^{2} \mathrm{~s}^{-1}, E k m=10 \mathrm{~W} \mathrm{~m}^{-2}, Z=100 \mathrm{~m}$. We then used the difference in the calculated air-sea gas exchange parameter values as a first-order approximation for the uncertainty due to choice of physical parameters. The choice of physical parameters differs slightly from decade to decade, perhaps because of differences in lateral processes (such as eddies) that are not resolved in the model, or trends in unresolved biases in the NCEP data. For the time period 1978 to 1989, we also performed calculations with three sets of physical parameters: (1) the best physical parameters $K z=$ $3.6 \times 10^{-5} \mathrm{~m}^{2} \mathrm{~s}^{-1}, Z=100 \mathrm{~m}$, and $E \mathrm{~km}=5.5 \mathrm{~W} \mathrm{~m}^{-2}$; (2) $\mathrm{Kz}=8 \times 10^{-5} \mathrm{~m}^{2} \mathrm{~s}^{-1}, E k m=$ $5 \mathrm{~W} \mathrm{~m}^{-2}, Z=100 \mathrm{~m}$; and (3) $K z=2 \times 10^{-5} \mathrm{~m}^{2} \mathrm{~s}^{-1}, E k m=10 \mathrm{~W} \mathrm{~m}^{-2}, Z=100 \mathrm{~m}$.

\section{Sensitivity study: Constraints on air-sea gas exchange parameters from the noble gases}

\section{a. Model results: Noble gas behavior}

The model shows that the individual noble gases have different signatures in the mixed layer (Fig. 2) and the upper ocean (Fig. 3) because the noble gases have a range of physical properties. We measure and model concentrations of the noble gases. However, to ease interpretation, all noble gas results are presented here as saturation anomalies, $\Delta$, which are defined as

$$
\Delta=\left(\frac{C_{i, w}}{C_{i, e q}}-1\right) \times 100
$$

where $C_{i, w}$ is the concentration of gas $i$ in the water and $C_{i, e q}$ is the concentration of gas $i$ at equilibrium. Positive (negative) saturation anomalies reflect that the gas is supersaturated 


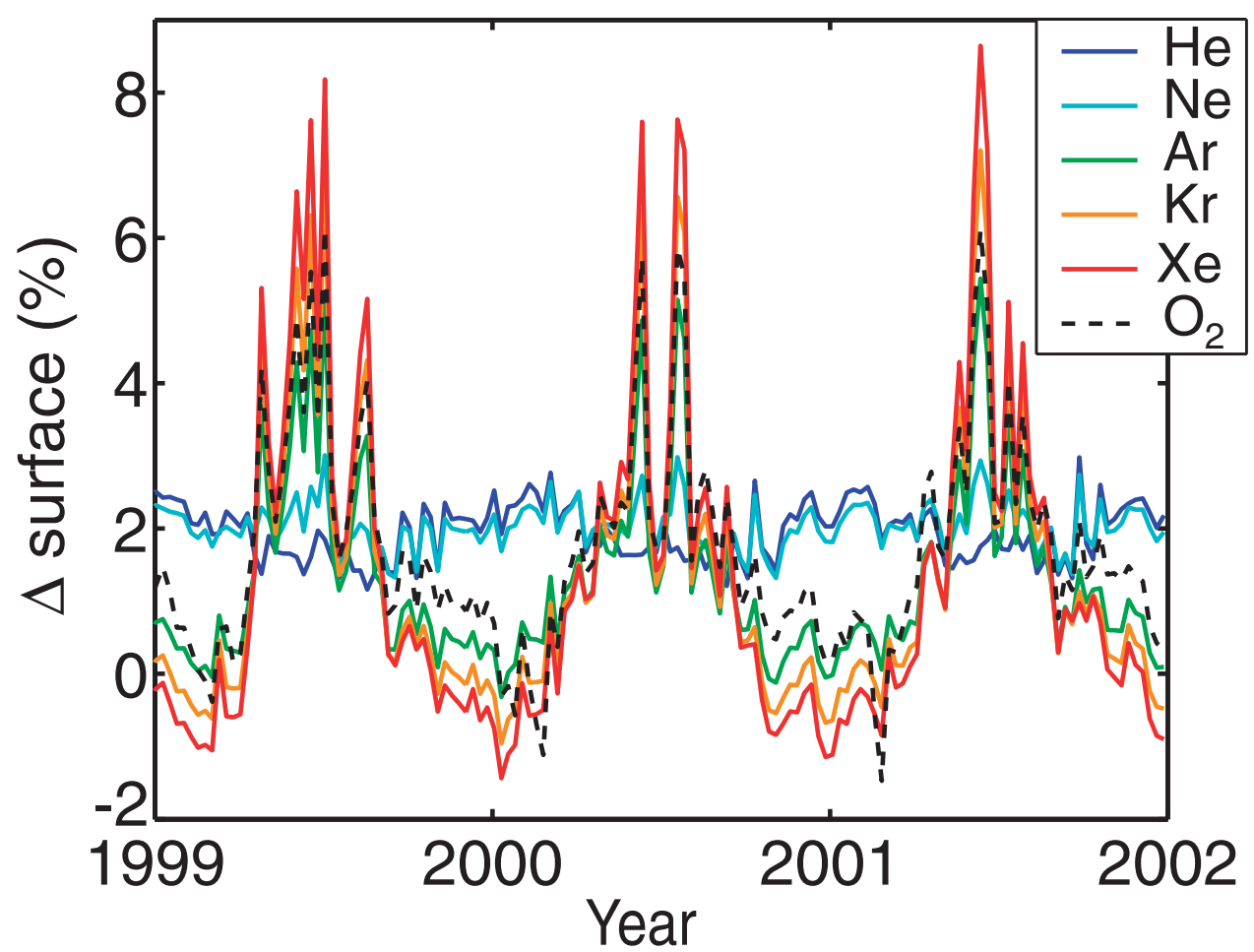

Figure 2. Surface (mixed layer) saturation anomalies ( $\left.\Delta_{\text {surface }}\right)$ for the five noble gases and oxygen as predicted by the model using reference case model parameters. Note that $\mathrm{He}$ and $\mathrm{Ne}$ form one group with $\Delta \mathrm{He}$ at a maximum in the winter, whereas $\mathrm{Ar}, \mathrm{Kr}, \mathrm{Xe}$, and $\mathrm{O}_{2}$ form a second group and are at a maximum in the summer. Furthermore, this second group of gases has a much larger range in surface saturation anomalies.

(undersaturated), and the magnitude of the saturation anomalies corresponds to the magnitude of the departure from equilibrium. Although a similar pattern of saturation anomalies is seen from one year to another, the exact magnitude of the saturation anomalies differ each year because the saturation anomalies are driven by physical processes, such as wind forcing, mixed layer depth, and mixed layer temperature, which also differ each year.

Helium and Ne are relatively insoluble, with a weak solubility dependence on temperature (Weiss, 1971; Hamme and Emerson, 2004). Helium and Ne are thus sensitive to both air injection processes and to diffusive gas exchange. The model shows the maximum surface saturation anomalies of $\mathrm{He}$ are in the winter, when the winds are strongest causing large air injection events. The surface saturation anomalies of $\mathrm{He}$ and $\mathrm{Ne}$ are thus good choices for observational metrics for air injection magnitude. The difference between the winter and summer surface saturation anomalies, the seasonal amplitude, is used as the observational metric in order to minimize the effect of any systematic error in the solubility 

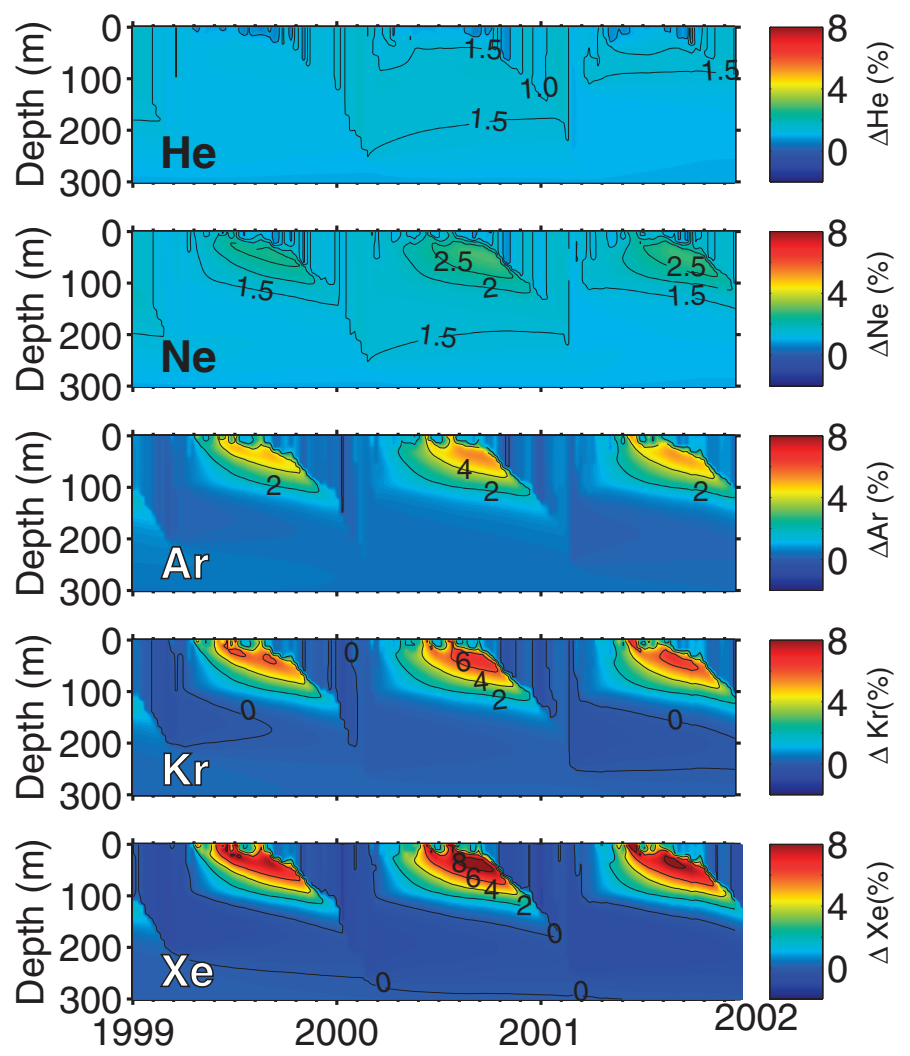

Figure 3. Saturation anomalies for all five noble gases in the upper $300 \mathrm{~m}$ of the water column as predicted by the model using reference case model parameters. Contours are drawn at $0.5 \%$ spacing for $\mathrm{He}$ and $\mathrm{Ne}$ and at $2 \%$ spacing for $\mathrm{Ar}, \mathrm{Kr}$, and $\mathrm{Xe}$. The range in Xe saturation anomalies is four times that of He saturation anomalies.

functions of the gases. Additionally, since $\mathrm{He}$ and $\mathrm{Ne}$ have similar solubilities but different diffusivities, the ratio between $\mathrm{He}$ and $\mathrm{Ne}$ surface saturation anomalies is a useful observational metric for diffusively mediated processes, such as the magnitude of partially trapped bubbles.

In contrast, $\mathrm{Kr}$ and $\mathrm{Xe}$ are more soluble with a strong solubility dependence on temperature (Wood and Caputi, 1966; Weiss and Kyser, 1978), and thus Kr and Xe respond primarily to diffusive gas exchange. Saturation anomalies of $\mathrm{Kr}$ and $\mathrm{Xe}$ are at maximum during the summer. In the summer the ocean warms due to subsurface solar heating. Krypton and Xe are less soluble in warmer water leading to a supersaturation and thus a flux of $\mathrm{Kr}$ and $\mathrm{Xe}$ out of the ocean. However, the flux is not strong enough to remove all the excess gas resulting in large positive saturation anomalies of up to $6 \%$ for $\mathrm{Kr}$ and $9 \%$ for Xe in the mixed layer. Below the mixed layer, the gases cannot be directly expelled to 


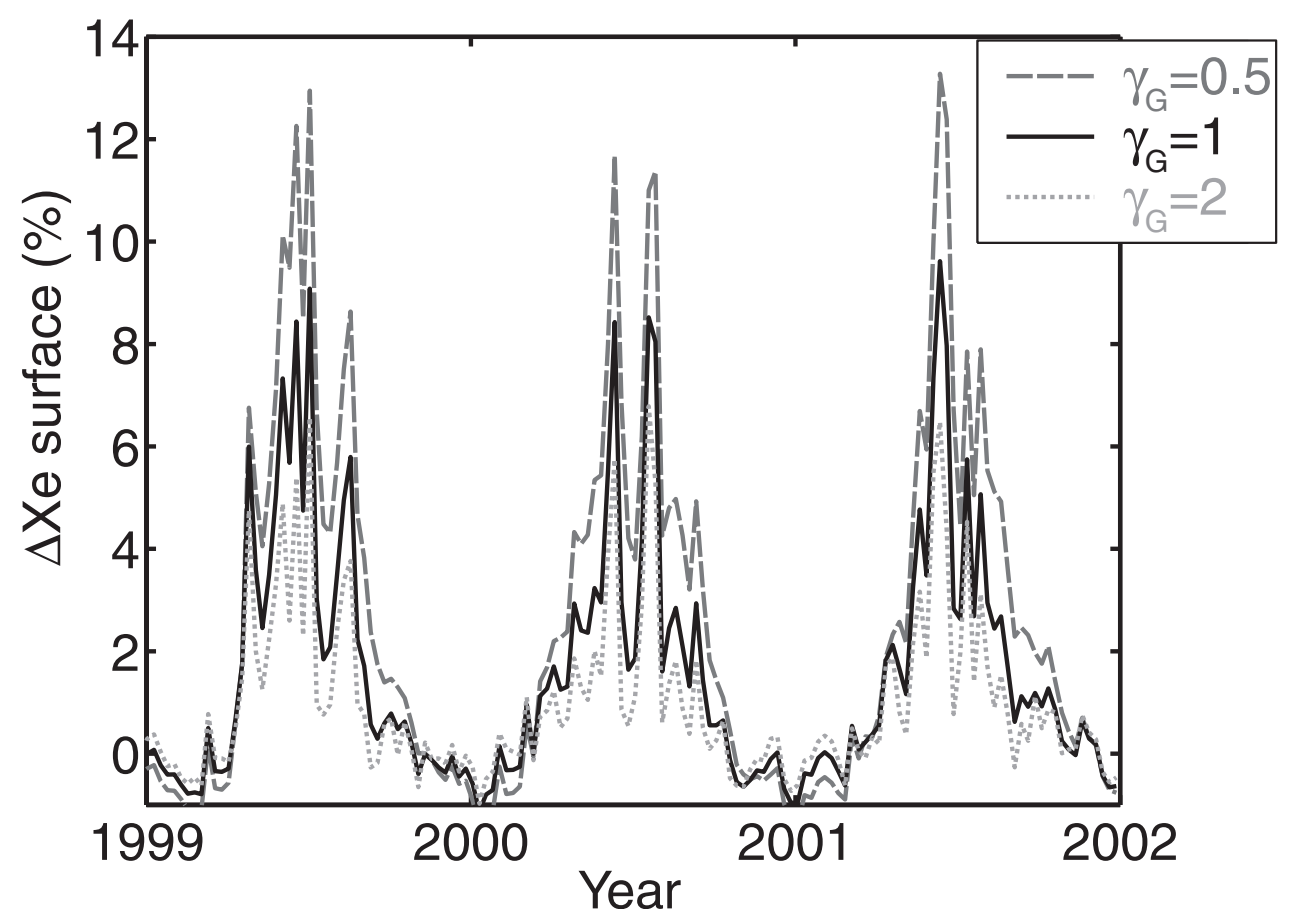

Figure 4. The Xe surface saturation anomaly for model runs with three different values of the model parameter $\gamma_{G}: \gamma_{G}=0.5(---), \gamma_{G}=1(-)$, and $\gamma_{G}=2(\cdots)$. The Xe surface saturation anomaly is a useful observational metric for gas exchange magnitude because it is sensitive to changes in $\gamma_{G}$. In the summer, Xe is supersaturated. As $\gamma_{G}$ increases, the flux of Xe out of the mixed layer increases, less $\mathrm{Xe}$ is left in the mixed layer, and thus $\Delta \mathrm{Xe}$ decreases.

the atmosphere, resulting in large saturation anomalies that persist for months. The seasonal amplitude of $\mathrm{Kr}$ and $\mathrm{Xe}$ surface saturation anomalies are useful observational metrics for diffusive gas exchange, since as the gas exchange flux out of the mixed layer increases, $\Delta \mathrm{Kr}$ and $\Delta \mathrm{Xe}$ in the mixed layer decrease (Fig. 4).

Argon has a solubility in between that of $\mathrm{Ne}$ and $\mathrm{Kr}$ (Weiss, 1970) and thus has an intermediate response, responding both to air injection events (though more weakly than does $\mathrm{He}$ and $\mathrm{Ne}$ ) and to diffusive gas exchange. Argon is especially useful because it has a solubility and diffusivity similar to $\mathrm{O}_{2}$, allowing Ar to be an abiotic analogue of $\mathrm{O}_{2}$. The difference between $\mathrm{Ar}$ and $\mathrm{O}_{2}$ seen in Figure 2 is a direct result of biological production affecting only $\mathrm{O}_{2}$. In order to quantify biological production, we chose as an observational metric the difference between $\mathrm{Ar}$ and $\mathrm{O}_{2}$ saturation anomalies at $55 \mathrm{~m}$ depth. We found that a depth of $55 \mathrm{~m}$ for the saturation anomalies yielded the greatest sensitivity to biological production because $\Delta \mathrm{Ar}$ and $\Delta \mathrm{O}_{2}$ are at maxima at that depth during the summer.

By using observational metrics that incorporated all five noble gases and $\mathrm{O}_{2}$, we had six 
Table 2. Uncertainty on model parameters as determined from individual observational metrics and the corresponding slopes as calculated from the partial derivative method. For each model parameter, the observational metrics that offer the tightest constraints on the parameter are listed as well as the slope, $r^{2}$ value, and estimated measurement uncertainty in the observational metric. For a given model parameter, steeper slopes and smaller measurement uncertainties result in tighter constraints. Since $\gamma_{G}, \gamma_{A c}, \gamma_{A p}$ have the same reference values, it is possible to compare slopes between those parameters. For a definition of slope and constraint, see Eq. 11. The units of the slope are $\%$ for $\gamma_{G}, \gamma_{A c}, \gamma_{A p}$ and are $\% \mathrm{~mol}^{-1} \mathrm{~m}^{2}$ y for $\gamma_{P} . \Delta_{\text {surface }}$ refers to a surface saturation anomaly, $\Delta_{55}$ to saturation anomaly at $55 \mathrm{~m}$ depth, w to winter average, and s to summer average.

\begin{tabular}{|c|c|c|c|c|c|}
\hline $\begin{array}{c}\text { Model } \\
\text { parameter }\end{array}$ & $\begin{array}{l}\text { Uncertainty of } \\
\text { model parameter }\end{array}$ & $\begin{array}{l}\text { Observational metric } \\
(\%)\end{array}$ & Slope & $r^{2}$ & $\begin{array}{c}\text { Estimated } \\
\text { measurement } \\
\text { uncertainty in } \\
\text { observational } \\
\text { metric }(\%)\end{array}$ \\
\hline \multirow[t]{4}{*}{$\gamma_{G}$} & $6 \%$ & $\Delta \mathrm{Xe}_{\text {surface }} \mathrm{W}-\mathrm{s}$ & 3.5 & 0.996 & 0.2 \\
\hline & $6 \%$ & $\Delta \mathrm{Ar}_{\text {surface }} \mathrm{W}-\mathrm{S}$ & 1.5 & 0.998 & 0.1 \\
\hline & $8 \%$ & $\Delta \mathrm{Kr}_{\text {surface }} \mathrm{W}-\mathrm{S}$ & 2.4 & 0.997 & 0.2 \\
\hline & $17 \%$ & $\Delta \mathrm{He}_{\text {surface }} \mathrm{W}-\mathrm{s}$ & -0.61 & 0.995 & 0.1 \\
\hline \multirow[t]{5}{*}{$\gamma_{A c}$} & $20 \%$ & $\Delta \mathrm{Ne}_{\text {surface }} \mathrm{W}-\mathrm{S}$ & -0.49 & 1 & 0.1 \\
\hline & $22 \%$ & $\Delta \mathrm{He}_{\text {surface }} \mathrm{W}-\mathrm{s}$ & -0.45 & 1 & 0.1 \\
\hline & $21 \%$ & $\Delta \mathrm{Ne}-\Delta \mathrm{Ar}_{\text {surface }} \mathrm{W}$ & 0.68 & 1 & 0.14 \\
\hline & $23 \%$ & $\Delta \mathrm{Ne}-\Delta \mathrm{Xe}_{\text {surface }} \mathrm{W}$ & 0.96 & 1 & 0.22 \\
\hline & $25 \%$ & $\Delta \mathrm{Ne}-\Delta \mathrm{Kr}_{\text {surface }} \mathrm{W}$ & 0.85 & 1 & 0.22 \\
\hline \multirow[t]{3}{*}{$\gamma_{A p}$} & $26 \%$ & $\Delta \mathrm{He}_{\text {surface }} / \Delta \mathrm{Ne}_{\text {surface }}$ & 0.38 & 0.995 & 0.1 \\
\hline & $36 \%$ & $\Delta \mathrm{He}_{\text {surface }} \mathrm{W}-\mathrm{S}$ & -0.28 & 0.9997 & 0.1 \\
\hline & $39 \%$ & $\Delta \mathrm{Ne}_{\text {surface }} \mathrm{W}-\mathrm{S}$ & -0.25 & 0.9998 & 0.1 \\
\hline$\gamma_{P}$ & $0.2 \mathrm{~mol} \mathrm{O}_{2} \mathrm{~m}^{-2} \mathrm{y}^{-1}$ & $\Delta \mathrm{Ar}_{55}-\Delta \mathrm{O}_{2,55} \mathrm{~s}$ & 1.1 & 1 & 0.22 \\
\hline
\end{tabular}

constraints. Additional constraints came from using the saturation anomalies of the gases in the surface or at any other depth, in the winter or the summer or annual average, or singly or in combination. Although not all of these constraints are strictly independent, multiple observational metrics allowed us to quantitatively distinguish among air-sea gas exchange processes.

\section{b. Quantifying the constraints}

The partial derivative method reveals which observational metrics are useful for constraining the air-sea gas exchange parameters. The constraints, slopes, and $r^{2}$ values of some of the observational metric/model parameter linear relationships are listed in Table 2. The suitability of an observational metric to the quantification of a given model parameter can readily be seen from the table or from a plot of the observational metric as a function of the model parameter (Fig. 5). A steeper slope of the linear regression corresponds to a stronger sensitivity of the observational metric to the parameter (see Eq. 11). For example, 
Gas Exchange Magnitude

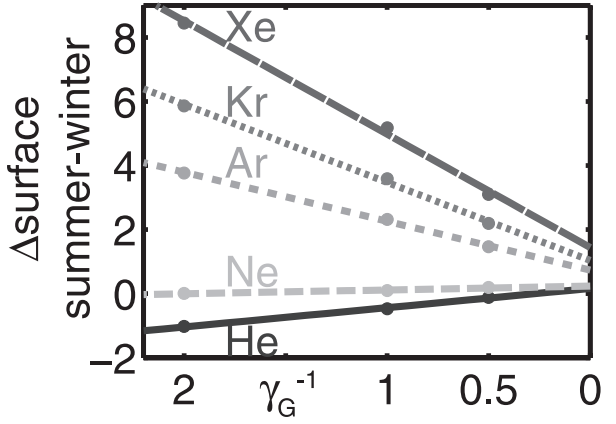

Complete Bubble Trapping

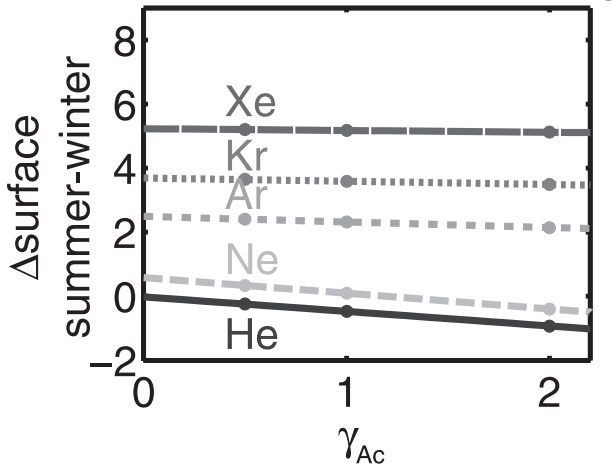

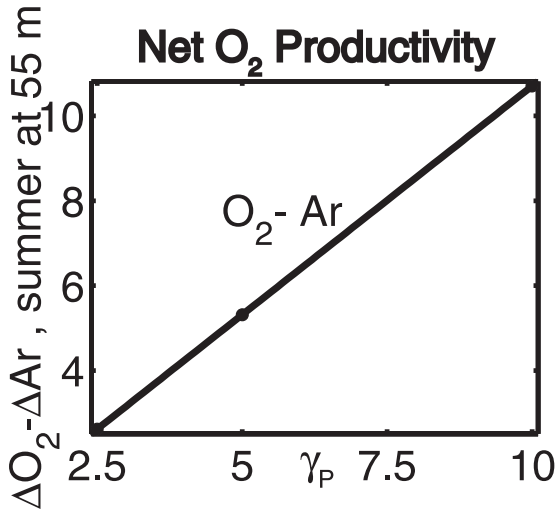

Partial Bubble Trapping

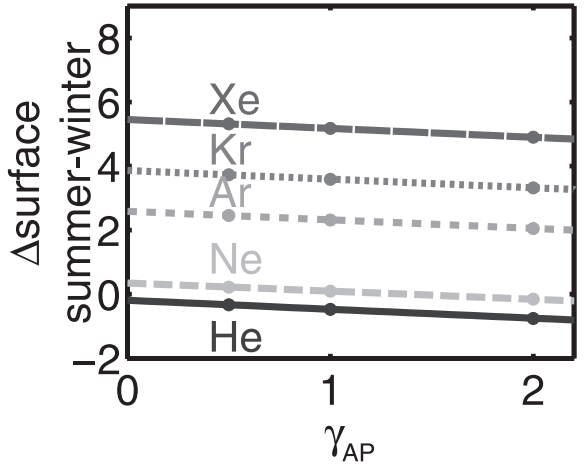

Figure 5. The Linearizations: the observational metrics are plotted as a function of model parameter and then a linear relationship is calculated. The slope is a reflection of how sensitive the observational metric is to the parameter - a steep slope implies a sensitive metric. The observational metrics are plotted as a function of the inverse of the gas exchange parameter $\gamma_{G}$ because the saturation anomalies of the noble gases are inversely proportional to gas exchange.

note that the He surface saturation anomaly vs. complete bubble trapping has a steep slope signifying a strong constraint, whereas the Xe surface saturation anomaly vs. complete bubble trapping has a very shallow slope signifying a weak constraint. Because the linearizations for complete bubble trapping are similar to those for partial bubble trapping, observational metrics that combined various noble gases were used to distinguish between complete and partial trapping. In particular, the difference between $\Delta \mathrm{Ne}$ and $\Delta \mathrm{Ar}$ provided a useful constraint for complete bubble trapping. For diffusive gas exchange magnitude, $\gamma_{G}$, the observational metrics were plotted as a function of $\gamma_{G}^{-1}$ since one would expect saturation anomalies of the gases to be inversely proportional to the strength of gas exchange. In addition, for $\gamma_{G}$, the slope is defined as the $\Delta$ (observational metric) $/ \Delta\left(\gamma_{G}{ }^{-1}\right)$.

The advantage of the partial derivative method is that it allows determination of precisely which gases, or observational metrics, best constrain a given parameter. The 
Table 3. Constraints on the air-sea gas exchange model parameters calculated using the full inverse method. All uncertainties are $1 \sigma$ values. First listed is the uncertainty of the model parameter with a fixed choice of physical parameters, second the additional uncertainty due to the choice of physical parameters (i.e. uncertainty due to $1 \mathrm{D}$ model physics), and third the total uncertainty on the parameter, calculated by adding the above uncertainties in quadrature. Because there is a large negative covariation between partial and complete trapping, the total air injection flux, $F_{A I}$, has an uncertainty of approximately $14 \%$.

$\begin{array}{cccc} & \begin{array}{c}\text { Uncertainty } \\ \text { from full } \\ \text { inverse } \\ \text { method }\end{array} & \begin{array}{c}\text { Uncertainty } \\ \text { from physical } \\ \text { parameters }\end{array} & \begin{array}{c}\text { Total } \\ \text { uncertainty }\end{array} \\ \text { Model parameter } & 4 \% & 10 \% & \mathbf{1 1 \%} \\ \gamma_{G} & 12 \% & 17 \% & \mathbf{2 0 \%} \\ \gamma_{A c} & 21 \% & 15 \% & \mathbf{2 6 \%} \\ \left.\gamma_{A p}-2 \mathrm{y}^{-1}\right) & 0.2 & 1.5 & \mathbf{1 . 5}\end{array}$

disadvantage is the actual constraints determined from the partial derivative method are not necessarily accurate as they assume we have only one observational metric and only one model parameter at a time. Thus we need the full inverse method in order to determine simultaneously all of the constraints on air-sea gas exchange parameters as offered by a noble gas time-series (Table 3). Because we have multiple observational metrics, the constraints offered by the full inverse method are slightly tighter than those offered by the partial derivative method. For example, $\gamma_{G}$ can be constrained to $6 \%$ in the partial derivative method and to $4 \%$ in the full inverse method. When we include the additional uncertainty due to choice of physical parameters, the total uncertainty for $\gamma_{G}$ is $11 \%$. Estimates of net biological production could be constrained to $\pm 0.2 \mathrm{~mol} \mathrm{O}_{2} \mathrm{~m}^{-2} \mathrm{y}^{-1}$ if $K_{z}$ were known perfectly. However, uncertainties in $K_{z}$ increase the uncertainty in net biological production to $1.5 \mathrm{~mol} \mathrm{O}_{2} \mathrm{~m}^{-2} \mathrm{y}^{-1}$. Biological production is sensitive to the choice of $K_{z}$ because there is a very sharp gradient in $\mathrm{O}_{2}$, but not in $\mathrm{Ar}$, below the euphotic zone. In this respect, Ar is not a perfect abiogenic analog of oxygen.

The magnitude of the complete bubble trapping flux, $F_{C}$, can be constrained to $12 \%$ and the magnitude of the partial bubble trapping flux, $F_{P}$, can be constrained to $23 \%$, both significant improvements over other currently available techniques. If one includes the uncertainty due to possible variations in physical parameters, then the magnitude of the complete bubble trapping flux can be constrained to $20 \%$ and the magnitude of the partial bubble trapping flux can be constrained to $26 \%$. However, even with multiple gases, we have some difficulty in resolving the partitioning between partial trapping and complete trapping. The uncertainty in the total air injection flux, $F_{A I}$, is smaller than the uncertainty of either $F_{C}$ or $F_{P}$ because there is a large negative covariation between $\gamma_{A c}$ and $\gamma_{A p}$. The uncertainty on total air injection depends upon the gas and is smaller for the gases that are more influenced by air injection. For $\mathrm{He}, \mathrm{Ne}$, and Ar the uncertainty on $F_{A I}$ is $6 \%$. For $\mathrm{Kr}$ and $\mathrm{Xe}$, the uncertainty on $F_{A I}$ is $8 \%$ and $10 \%$ respectively. The choice of physical 
parameters adds another $12 \%$ uncertainty. The total uncertainty in air injection, averaged for the five gases, including uncertainty due to physical parameters, is $14 \%$. If we use a more pessimistic (and less realistic estimate) of the possible measurement uncertainties of the gases of $0.3 \%$ for all measurements, we can constrain $\gamma_{G}$ to $\pm 13 \%, \gamma_{A c}$ to $\pm 29 \%, \gamma_{A p}$ to $\pm 51 \%$ and $\gamma_{P}$ to $\pm 1.5 \mathrm{~mol} \mathrm{~m}^{-2} \mathrm{y}^{-1}$ (these uncertainties include the uncertainty due to physical parameters).

Ideally, one would use this method to determine $n$, the power dependency of gas exchange magnitude on wind speed. The exact nature of the wind-speed dependency of the gas transfer velocity is not well resolved. It may be a quadratic relationship (Wanninkhof, 1992), a cubic one (Wanninkhof and McGillis, 1999), or one following some fractional exponent. Unfortunately, however, Bermuda is not an ideal spot to study wind-speed dependency. The quadratic and cubic parameterizations are scaled to yield the same flux at the global average wind speed $\left(7.4 \mathrm{~m} \mathrm{~s}^{-1}\right)$ in order to match the global radiocarbon balance (Wanninkhof, 1992; Wanninkhof and McGillis, 1999). The average wind speed in Bermuda (7.1 $\mathrm{m} \mathrm{s}^{-1}$ for the period 1999-2002) is similar to the global average wind speed, making it difficult to distinguish between a quadratic and cubic parameterization. Additionally, the wind-speed distribution in Bermuda has a standard deviation of only $3.4 \mathrm{~m} \mathrm{~s}^{-1}$, and there are very few resolved large wind-speed events that would show a large difference between quadratic and cubic parameterizations.

We performed calculations with $n=3, n=2$, and $n$ as a tunable model parameter. The estimated uncertainties of the air-sea gas exchange parameters are similar whether we use $n=3$ or $n=2$. The value for the coefficient for the gas exchange flux (i.e. $7.9 \times 10^{-8} \mathrm{in} \mathrm{Eq}$. 2) and the value of $\gamma_{G}$ will change if a quadratic or cubic form is used but the relative uncertainty to which we can constrain $\gamma_{G}$ remains similar. If we use $n$ as a tunable model parameter, we can determine the power dependency to \pm 0.4 . However, due to the interplay of all the parameters in the flux equations, the constraints on the other parameters are weakened to $\pm 15 \%$ for $\gamma_{G}$, $\pm 27 \%$ for $\gamma_{A c}$, and $\pm 28 \%$ for $\gamma_{A p}$. For example, since the diffusive gas exchange flux $F_{G E}$ depends on both $n$ and $\gamma_{G}$, if $n$ can vary, then $\gamma_{G}$ must have a larger uncertainty as well. Although this method can in principle determine $n$, extrapolating a determination of $n$ made at the low wind speeds in Bermuda to higher wind speeds is unwarranted. Hence, in Bermuda, where there are low winds and only a small spread in wind speed, it is best to fix $n$ and determine the best value of $\gamma_{G}$ for $n=2$ and $\gamma_{G}$ for $n=3$. Researchers who wish to use parameterizations of gas exchange determined by this method could choose an $n$ that is appropriate for their study site and then use the corresponding coefficient and $\gamma_{G}$ as determined by this method.

We explored the sensitivity of these conclusions to assumptions of the power dependence of solubility and diffusivity ( $a$ and $b$ in Eq. 5), to choice of solubility functions and to selection of reference case values. If different combinations of $a$ and $b$ are used ( $a=1, b=$ $2 / 3 ; a=1, b=1 / 2 ;$ or $a=0.7, b=0.35$ ), the values of $\gamma_{A c}$ and $\gamma_{A p}$ change. However, the fractional constraints offered by the noble gases on the parameters do not differ significantly. Thus we should be able to use noble gases to constrain air-sea gas exchange 
parameterizations regardless of the functional form of the air injection equation. The choice of solubility function, those of Weiss $(1970,1971)$ or of Hamme and Emerson (2004), does not significantly affect how well the noble gases can be used to constrain air-sea gas exchange parameterizations in the sensitivity analysis. However, the choice of solubility function does affect the actual values for the parameters and thus it is essential to have accurate solubility functions for all the noble gases.

The fractional constraints on $\gamma_{G}$ and $\gamma_{P}$ remain the same regardless of reference case parameter values. However, the constraints on $\gamma_{A c}$ and $\gamma_{A p}$ change with reference case. $\gamma_{A c}$ and $\gamma_{A p}$ covary and thus some reference cases have larger $\gamma_{A C}$ and smaller $\gamma_{A p}$, resulting in a larger proportion of air injection due to complete trapping. In that case, the constraint on complete trapping becomes tighter but the constraint on partial trapping becomes looser. Overall, the constraint on total air injection remains $14 \%$ regardless of reference case.

\section{Example application: Time-series of helium, neon, and argon}

As a limited demonstration, we performed an example determination of air-sea gas exchange parameters using a monthly time-series of $\mathrm{He}, \mathrm{Ne}, \mathrm{Ar}$, and $\mathrm{O}_{2}$ measurements made at Station S from March, 1985 to February, 1988 (Spitzer, 1989; Spitzer and Jenkins, 1989). The results of this example analysis are limited because the data are only for three of the noble gases and yet above we show that it is necessary to have the heavier noble gases ( $\mathrm{Kr}$ and $\mathrm{Xe}$ ) in order to separate diffusive gas exchange and air injection. In addition, methods for collecting and measuring noble gas samples have improved greatly (Lott and Jenkins, 1998), so measurements made today would be of higher quality. Nonetheless, the exercise allows us a preliminary glance at seasonal air-sea gas exchange parameters in an oligotrophic subtropical gyre.

For the Spitzer (1989) data, samples for $\mathrm{He}$ and Ne were collected from Niskin bottles in copper tubes containing $45 \mathrm{~g}$ of seawater and were measured mass spectrometrically using peak height manometry. Samples for Ar were collected in copper tubes containing $13 \mathrm{~g}$ of seawater and were measured using isotope dilution mass spectrometry. For a more complete descriptions of methods, see Spitzer and Jenkins (1989).

The noble gas data are presented in Figure 6. The $1 \sigma$ analytical uncertainty of Ar measurements is $0.4 \%$ but the reproducibility of the samples from samples drawn from the same Niskin bottle is about $1 \%$. The $1 \sigma$ analytical uncertainty for $\mathrm{He}$ and $\mathrm{Ne}$ measurements is $0.2 \%$ and the reproducibility is similarly $1 \%$. (For comparison, in Section 4 for the sensitivity study, we assumed modern errors of $0.1 \%$. The errors are smaller in modern studies because of improved sampling procedures and because of averaging made possible by oversampling in space and time.) We attribute the large scatter of this data to artifacts associated with the early sampling method. In addition, some of the samples with large supersaturations may have been contaminated with bubbles trapped during sample collection.

We used the full inverse method with twelve observational metrics to quantify the four model parameters: $\gamma_{G}, \gamma_{A c}, \gamma_{A p}$, and $\gamma_{P}$. The observational metrics and associated $1 \sigma$ errors 

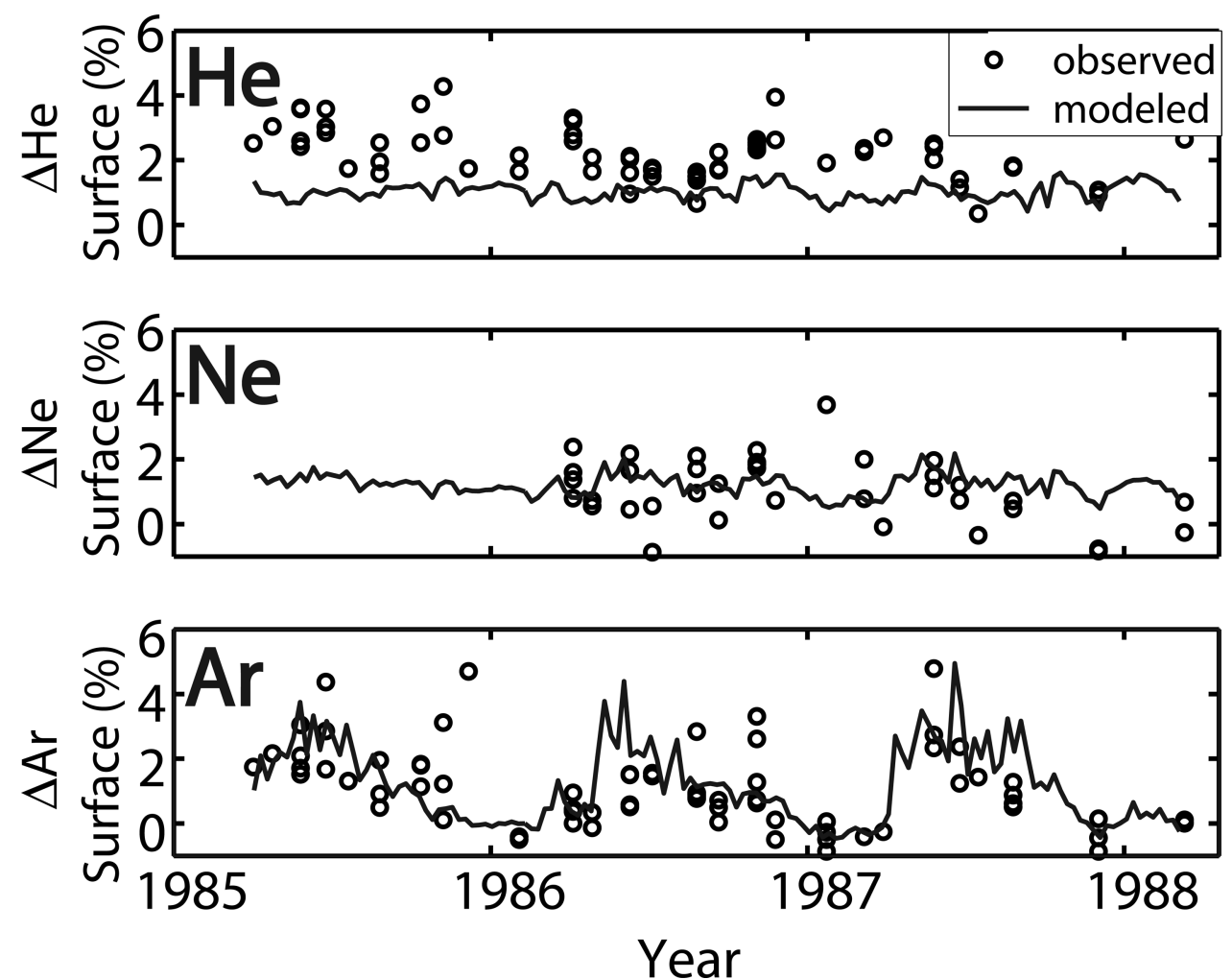

Figure 6. Monthly surface saturation anomalies (o) of $\mathrm{He}, \mathrm{Ne}$, and $\mathrm{Ar}$ at Station S, collected and measured by Spitzer (1989). The model results (-) are constructed using the model parameters determined from the full inverse calculation.

are listed in Table 4. Since the metrics are the mean of data over a given period, the errors are based on the combined standard error of the estimate of the mean (major component) and the analytical uncertainty (minor component). The error also includes the uncertainty in solubility functions for all observational metrics that are not based on differences between two saturation anomalies. If the metric is based on the difference between winter and summer values or between one gas and another, then any systematic uncertainties in solubility should cancel. For uncertainty in solubility functions, we use $1.5 \%, 0.3 \%$ and $0.13 \%$ for $\mathrm{He}, \mathrm{Ne}$ and Ar respectively (Hamme and Emerson, 2004). The He uncertainty is determined by the size of the correction we applied to the Weiss solubility functions.

The coefficient matrix, created from the slopes of the linearizations and weighted by the $1 \sigma$ errors in the observational metrics, is listed in Table 5. In a given column, a large absolute value of a coefficient implies the observational metric has a large part in determining the parameter. From the coefficient matrix, one can see Ar is more sensitive to diffusive gas exchange and less sensitive to complete bubble trapping than are $\mathrm{He}$ and $\mathrm{Ne}$. 
Table 4. Twelve observational metrics were calculated from the limited time series of $\mathrm{He}, \mathrm{Ne}, \mathrm{Ar}$ and $\mathrm{O}_{2}$ collected from 1985-1988 in the Sargasso Sea (Spitzer, 1989). The 1 $\sigma$ errors listed are the combined error due to the standard error of the estimate of the mean, the analytical uncertainty, and the solubility uncertainty if appropriate (see text for details). The model run was constructed using the air-sea gas exchange model parameters determined from the inverse calculation. $\Delta_{\text {surface }}$ refers to a surface saturation anomaly, $\Delta_{50}$ to saturation anomaly at $50 \mathrm{~m}$ depth, w to winter average, s to summer average, and a to annual average. The units of all saturation anomalies are $\%$.

\begin{tabular}{|c|c|c|}
\hline $\begin{array}{l}\text { Observational } \\
\text { metric }\end{array}$ & Data & Model \\
\hline$\Delta \mathrm{He}_{\text {surface }} \mathrm{s}-\mathrm{W}$ & $-0.19 \pm 0.4$ & -0.02 \\
\hline$\Delta \mathrm{Ne}_{\text {surface }} \mathrm{S}-\mathrm{W}$ & $-0.56 \pm 0.8$ & 0.54 \\
\hline$\Delta \mathrm{Ar}_{\text {surface }} \mathrm{S}-\mathrm{W}$ & $2.3 \pm 0.3$ & 2.5 \\
\hline$\Delta \mathrm{O}_{2,50}-\Delta \mathrm{Ar}_{50} \mathrm{~s}$ & $11 \pm 1$ & 11 \\
\hline$\Delta \mathrm{Ar}_{50} \mathrm{~s}-\mathrm{W}$ & $3.3 \pm 0.7$ & 4.9 \\
\hline$\Delta \mathrm{He}_{\text {surface }} \mathrm{W}$ & $2.3 \pm 0.4$ & 1.0 \\
\hline$\Delta \mathrm{Ne}_{\text {surface }} \mathrm{W}$ & $1.4 \pm 0.8$ & 0.93 \\
\hline$\Delta \mathrm{Ar}_{\text {surface }} \mathrm{W}$ & $-0.27 \pm 0.2$ & -0.05 \\
\hline$\Delta \mathrm{He}-\Delta \mathrm{Ne}_{\text {surface }}$ a & $1.0 \pm 0.3$ & -0.2 \\
\hline$\Delta \mathrm{He}_{\text {surface }} \mathrm{a}$ & $2.2 \pm 0.9$ & 1.0 \\
\hline$\Delta \mathrm{Ne}_{\text {surface }} \mathrm{a}$ & $1.0 \pm 1.1$ & 1.2 \\
\hline$\Delta \mathrm{Ar}_{\text {surface }} \mathrm{a}$ & $1.1 \pm 0.3$ & 1.1 \\
\hline
\end{tabular}

Nonetheless, all three gases are sensitive to all the air-sea gas exchange parameters, and thus, as expected, having only $\mathrm{He}, \mathrm{Ne}$, and Ar makes it difficult to quantitatively distinguish between air injection and gas exchange. In order to increase our ability to separate the two processes, we used additional observational metrics. For example, the seasonal amplitude of the saturation anomaly of Ar at $50 \mathrm{~m}$ depth is less influenced by air injection than the other metrics since air injection is less important for more soluble gases such as Ar.

Other observational metrics used include the difference between saturation anomalies of $\mathrm{O}_{2}$ and $\mathrm{Ar}$ at $50 \mathrm{~m}$ depth in order to constrain biological production and the difference between $\mathrm{He}$ and $\mathrm{Ne}$ surface saturation anomalies to constrain the fraction of bubbles completely vs. partially trapped. We also included the winter surface saturation anomalies of $\mathrm{He}, \mathrm{Ne}$, and $\mathrm{Ar}$ since these winter values are more sensitive to air injection and diffusive gas exchange than the seasonal amplitudes. Thus the winter values are valuable even though they have larger associated $1 \sigma$ errors (in order to take into account the error in solubility functions).

With twelve observational metrics and four parameters, the system is over-determined and can be solved using SVD to yield "best" values for the four tunable model parameters (Table 6). Uncertainties on the parameter values were determined from propagating the $1 \sigma$ error from the observational metrics through the SVD calculation and by including the error due to choice of physical parameters. Values of the air-sea gas exchange model parameters are robust to choice of physical parameters but differ by $50 \%$ according to 
Table 5. The slope matrix created from the linearizations of the analysis of the $\mathrm{He}, \mathrm{Ne}, \mathrm{Ar}$, and $\mathrm{O}_{2}$ time-series data, weighted by the $1 \sigma$ errors in the observational metrics. The observational metrics are listed in the first column. The parameters investigated are listed in the first row. A larger slope implies the observational metric responds strongly to changes in the parameter. $\Delta_{\text {surface }}$ refers to a surface saturation anomaly, $\Delta_{50}$ to saturation anomaly at $50 \mathrm{~m}$ depth, w to winter average, s to summer average, and a to annual average.

\begin{tabular}{|c|c|c|c|c|}
\hline $\begin{array}{c}\text { Observational } \\
\text { metric }\end{array}$ & $\gamma_{G}$ & $\gamma_{A c}$ & $\gamma_{A p}$ & $\gamma_{P}$ \\
\hline$\Delta \mathrm{He}_{\text {surface }} \mathrm{s}-\mathrm{W}$ & -1.9 & -1.3 & -1.0 & 0 \\
\hline$\Delta \mathrm{Ne}_{\text {surface }} \mathrm{S}-\mathrm{W}$ & -0.5 & -0.6 & -0.4 & 0 \\
\hline$\Delta \mathrm{Ar}_{\text {surface }} \mathrm{S}-\mathrm{W}$ & 2.9 & -0.6 & -1.0 & 0 \\
\hline$\Delta \mathrm{O}_{2}, 50^{-\Delta} \mathrm{Ar}_{50} \mathrm{~s}$ & 0.1 & 0 & 0 & 1.1 \\
\hline$\Delta \mathrm{Ar}_{50} \mathrm{~s}-\mathrm{W}$ & 0.6 & -0.1 & -0.2 & 0 \\
\hline$\Delta \mathrm{He}_{\text {surface }} \mathrm{W}$ & 3.8 & 2.7 & 1.3 & 0 \\
\hline$\Delta \mathrm{Ne}_{\text {surface }} \mathrm{W}$ & 1.9 & 1.5 & 0.6 & 0 \\
\hline$\Delta \mathrm{Ar}_{\text {surface }} \mathrm{W}$ & 2.5 & -0.6 & 0.1 & 0 \\
\hline$\Delta \mathrm{He}-\Delta \mathrm{Ne}_{\text {surface }} \mathrm{a}$ & -0.7 & 2.5 & 2.3 & 0 \\
\hline$\Delta \mathrm{He}_{\text {surface }} \mathrm{a}$ & 1.3 & 0.9 & 0.3 & 0 \\
\hline$\Delta \mathrm{Ne}_{\text {surface }} \mathrm{a}$ & 1.2 & 0.9 & 0.2 & 0 \\
\hline$\Delta \mathrm{Ar}_{\text {surface }} \mathrm{a}$ & 0.7 & 0.3 & 0.2 & 0 \\
\hline
\end{tabular}

whether the Hamme and Emerson (2004) solubility functions or the Weiss $(1970,1971)$ solubility functions are used. Though the total air injection fluxes are robust, the partitioning of these fluxes between complete and partial trapping is sensitive to choice of reference case. The magnitude of the biological production is sensitive to the choice of $K_{z}$. When we performed our calculations over a range of $K_{z}\left(2 \times 10^{-5}\right.$ to $\left.8 \times 10^{-5} \mathrm{~m}^{2} \mathrm{~s}^{-1}\right)$, the estimated biological production varied by $30 \%$. We included this source of error in the calculation of the $1 \sigma$ error of $\gamma_{P}$. Additionally, there is some ambiguity in the absolute magnitude of all parameters due to potential biases and errors associated with the NCEP reanalysis winds that were used to force the model.

Overall, the model parameters determined are reasonable. The gas exchange magnitude is $70 \% \pm 70 \%$ of that predicted by Wanninkhof and McGillis (1999). The net biological production is $9 \pm 3 \mathrm{~mol} \mathrm{O}_{2} \mathrm{~m}^{-2} \mathrm{y}^{-1}$, which is equivalent to $6 \pm 2 \mathrm{~mol} \mathrm{C} \mathrm{m}^{-2} \mathrm{y}^{-1}$ or

Table 6. Model parameter values as determined by the full inverse method (SVD) using the He, Ne, Ar and $\mathrm{O}_{2}$ time-series data.

Model

parameter

Description

Determined value

$\gamma_{G}$
$\gamma_{A c}$
$\gamma_{A p}$
$\gamma_{P}$

Magnitude of diffusive gas exchange

$0.7 \pm 0.7$

Magnitude of complete trapping component of air injection

$0.5 \pm 1$

Magnitude of partial trapping component of air injection

Magnitude of net biological production

$0.4 \pm 1$

$9 \pm 3 \mathrm{~mol} \mathrm{O}_{2} \mathrm{~m}^{-2} \mathrm{y}^{-1}$ 
$0.9 \pm 0.3 \mathrm{~mol} \mathrm{~N} \mathrm{~m}^{-2} \mathrm{y}^{-1}$ using the revised Redfield ratios of Anderson and Sarmiento (1994). Although this estimate is based on an idealized oxygen profile, it is similar to a recent estimate of new production determined using the ${ }^{3} \mathrm{He}$ flux gauge approach of $0.84 \pm$ $0.26 \mathrm{~mol} \mathrm{~N} \mathrm{~m}^{-2} \mathrm{y}^{-1}$ (Jenkins and Doney, 2003). It is slightly higher than several previous biogeochemical estimates of production in the Sargasso Sea (Jenkins and Goldman, 1985; Jenkins, 1988; Spitzer and Jenkins, 1989; Gruber et al., 1998).

We investigated how well the model could match the data by using the best parameters as determined from the SVD (Table 6) to run the model. The resulting model run results are plotted with the data in Figure 6. Observational metrics calculated from the model run are listed in Table 4. The model predicts He saturation anomalies consistently lower than the observed $\mathrm{He}$, perhaps because of systematic errors in sampling collection, sampling analysis or in the solubility of He. The model run allows us to quantify and compare the fluxes due to diffusive gas exchange, complete bubble trapping, and partial bubble trapping (Fig. 7). Although $\mathrm{Kr}$ and $\mathrm{Xe}$ were not measured, the model can use the air-sea gas exchange parameters determined from the $\mathrm{He}, \mathrm{Ne}$, and $\mathrm{Ar}$ data to calculate diffusive gas exchange and air injection fluxes for $\mathrm{Kr}$ and $\mathrm{Xe}$ as well. For the insoluble gases $\mathrm{He}$ and $\mathrm{Ne}$ (not shown), the diffusive gas exchange flux is similar in magnitude and opposite in direction to the air injection flux. Large air injection events are mirrored by large diffusive gas exchange fluxes. Additionally, the air injection flux is primarily due to complete trapping. For the more soluble gases $\mathrm{Kr}$ (not shown) and $\mathrm{Xe}$, the opposite is true. The diffusive gas exchange flux is larger than the air injection flux and there are many diffusive gas exchange events that are not associated with air injection events. Because these gases are soluble with a strong temperature dependence to solubility, air injection is less important and diffusive gas exchange is primarily driven by thermal forcing. The air injection flux of $\mathrm{Kr}$ and $\mathrm{Xe}$ is primarily due to partial trapping. The behavior of $\mathrm{Ar}$ is intermediate between $\mathrm{He}$ and Xe.

We explored the sensitivity of the calculations to the power dependency of solubility and diffusivity used in the partial bubble trapping equation ( $a$ and $b$ in Eq. 5). We repeated all calculations for three different cases of $a$ and $b\left(\alpha D^{2 / 3}, \alpha D^{1 / 2}, \alpha^{0.7} D^{0.35}\right)$. If $\alpha D^{1 / 2}$ or $\alpha^{0.7} D^{0.35}$ is used, then negative values for $\gamma_{A p}$ result from the SVD calculation. This situation is clearly unphysical. One can, however, achieve positive values for all parameters if one does not use the two observational metrics of winter average $\Delta \mathrm{Ar}$, and $\Delta \mathrm{He}-\Delta \mathrm{Ne}$. This implies that in the $\alpha D^{1 / 2}$ or $\alpha^{0.7} D^{0.35}$ cases, it is possible to achieve the general signatures of the gases but is impossible to match the winter average of $\Delta \mathrm{Ar}$ or to achieve the proper differences between the saturation anomalies of $\mathrm{He}$ and $\mathrm{Ne}$. If one uses the results from the SVD where those two observational metrics were excluded, the total fluxes for air injection and gas exchange are a factor of two larger than the results for $\alpha D^{2 / 3}$ case calculated with all observational metrics. The results for $\alpha D^{1 / 2}$ or $\alpha^{0.7} D^{0.35}$ are similar to the results for a calculation performed with $\alpha D^{2 / 3}$ but without the same two observational metrics. Thus both choice of observational metrics and power dependency of $\alpha$ and $D$ are important. Differences in power dependency are not merely notational - they have 

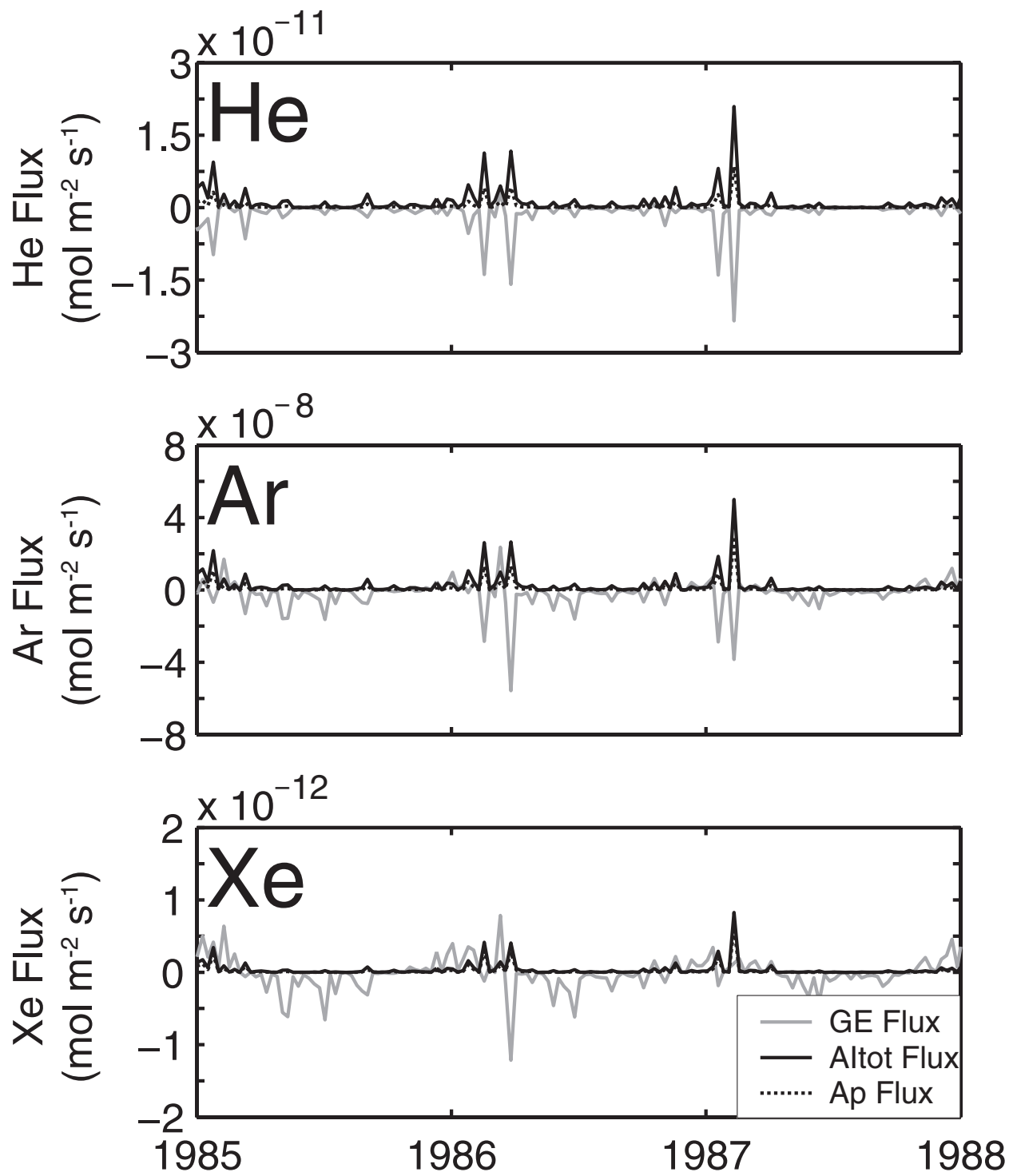

Figure 7. Model results for the diffusive gas exchange flux $F_{G E}(-)$, total air injection flux $F_{A I}(-)$, and partial air injection flux $F_{P}(--)$ for $\mathrm{He}, \mathrm{Ar}$, and $\mathrm{Xe}$. The complete air injection flux $F_{C}$ is equal to the difference between the $F_{A I}$ and $F_{P}$ curves. The fluxes are calculated using the parameter values determined from the full inverse method. Note the difference in vertical scales used for each gas. For He, the gas exchange flux is approximately equal in magnitude and opposite in sign to the air injection flux whereas for $\mathrm{Xe}$, the gas exchange flux is typically much larger than the air injection flux. 
important implications for the total fluxes of gases. Since isotopes have similar solubilities but different diffusivities, isotopic ratios of the noble gases (e.g. ${ }^{20} \mathrm{Ne} /{ }^{22} \mathrm{Ne},{ }^{36} \mathrm{Ar} /{ }^{40} \mathrm{Ar}$ ) could potentially be used to better constrain the power dependency of the diffusivity of partial bubble trapping.

The exercise performed here differs from the work of Spitzer and Jenkins (1989) in several ways. We used NCEP reanalysis winds and heat fluxes to force the model, a cubic parameterization of equilibrium gas exchange, and a different formulation of air injection processes. Spitzer and Jenkins used climatological winds and heat fluxes, a three-step linear parameterization of equilibrium gas exchange (Liss and Merlivat, 1986), and a formulation of air injection where partial bubble trapping depended only on the diffusivity of the gas. In addition, Spitzer and Jenkins did not use Ne data and used only one year of $\mathrm{He}, \mathrm{Ar}$, and $\mathrm{O}_{2}$ data. Our results differ from Spitzer and Jenkins in that we find that the majority of bubbles are completely trapped, whereas they found that partial trapping was dominant. The biological production we estimate is $45 \%$ larger than the Spitzer and Jenkins estimate. It is difficult to directly compare estimates of gas exchange since we use different parameterizations.

The uncertainties on the model parameters are quite large - much larger than the expected constraints on model parameters from the theoretical noble gas sensitivity study that we report in Section 4.b. These large uncertainties result from the limited nature of the data. First, we only have data for three noble gases and yet above we show we need all five noble gases to separate the air injection and diffusive gas exchange processes. Second, the data have large uncertainties associated with sample collection and measurements. Current methods for sample collection and measurement have improved greatly in the last two decades. In the expected constraints reported in Section 4.b, we assumed measurement uncertainties of $0.1 \%$ for $\mathrm{He}, \mathrm{Ne}$ and $\mathrm{Ar}$, and $0.2 \%$ for $\mathrm{Kr}$ and $\mathrm{Xe}$. Hence the large uncertainties in this exercise do not contradict the results of Section 4.b. Rather, they show that though we have a powerful method, we need to have the appropriate data in order to use the method. Additionally, some uncertainty may result from the real ocean being more complex than our ideal model assumes.

\section{Conclusions}

Noble gases are useful tools for quantifying air-sea gas exchange parameters since the difference in physical properties of the gases allows separation of processes. Model calculations show that a time-series of all five noble gases and $\mathrm{O}_{2}$ can constrain air-sea gas exchange parameters more tightly than can other currently available methods. An additional advantage of this noble gas method is that it allows the study of gas exchange from empirical data on a larger scale than is possible with purposeful tracer release or laboratory experiments.

The potential constraints on the air-sea gas exchange parameters were calculated using only the uncertainty due to expected measurement capability and to choice of physical parameters. Additional sources of potential uncertainty that were not included in the 
analysis but would serve to increase the calculated uncertainties (loosen the constraints) of parameters include variability in sample collection due to small-scale processes such as Langmuir cells and mesoscale processes such as eddies. We can try to average over the small-scale processes by taking multiple samples in the mixed layer and over the mesoscale processes by using a multi-year time-series with monthly resolution. Furthermore, satellite imagery can be used to assess the influence of eddies and lateral processes.

Systematic uncertainties include a bias against sampling in high-wind events and any errors in the solubility functions of the noble gases. The former is mitigated because noble gas signatures integrate over a few weeks so samples only need be collected within a few weeks of the storm event. In addition samples can be collected with a moored noble gas sampler that can collect samples in any conditions (Hood, 1998). However, wind speed data can be problematic at high wind speeds, thus making interpretation of the noble gas data difficult. Although systematic biases in solubility can be partially mitigated by using seasonal amplitudes of the noble gases saturation anomalies, this study illustrates the need for accurate determination of the solubilities of all the noble gases.

As no data yet exist for all five noble gases, we presented an example calculation using a time-series of only three of the noble gases in order to illustrate the method and to calculate some initial values for air-sea gas exchange parameters in the Sargasso Sea. Ongoing work includes collection of a time-series of all five noble gases in order to exploit the full potential of this method. Current improvements in sample collection and extraction (Lott and Jenkins, 1998) and in mass spectrometry, including advances in the technique of using cryogenics to separate the noble gases (Lott, 2001), make such a time-series feasible. In April 2003, we started measuring a three-year time series of all five noble gases. That data combined with the method presented here (as well as with a full nonlinear optimization) will allow an accurate determination of air-sea gas exchange parameters based on empirical measurements. These estimates are unique in that they cover the time-scale (several weeks to months rather than days or years) and spatial scale (regional average rather than local patch or global scope) that is important to understanding the biogeochemical cycling of gases.

Acknowledgments. This work was supported by the National Science Foundation Chemical Oceanography program (OCE-0221247) and by the Department of Defense (graduate fellowship to RHRS). We would like to thank Don Rice for his support and encouragement, Roberta Hamme for the use of MATLAB code for the solubility functions of the noble gases, and Burkard Baschek and Dierdre Toole for useful discussions. We also thank Michael Bender and Steven Emerson for their helpful reviews.

\section{APPENDIX}

Symbols

$A_{c} \quad$ constant coefficient equal to $1.4 \times 10^{-3}$ for complete bubble trapping flux

$A_{p} \quad$ constant coefficient equal to $2 \times 10^{5}$ for partial bubble trapping flux exponent for power dependency of $\alpha$ in partial bubble trapping flux 
$b \quad$ exponent for power dependency of diffusivity in partial bubble trapping flux

$C_{i, e q} \quad$ equilibrium concentration of gas $i$ in water $\left(\right.$ moles $\left.\mathrm{m}^{-3}\right)$

$C_{i, w} \quad$ concentration of gas $i$ in water $\left(\right.$ moles $\left.\mathrm{m}^{-3}\right)$

$D_{i} \quad$ diffusivity coefficient of gas $i\left(\mathrm{~m}^{2} \mathrm{~s}^{-1}\right)$

Ekm parameter used in model to compensate for the Ekman heat convergence $\left(\mathrm{W} \mathrm{m}^{-2}\right)$

$F_{A I} \quad$ gas flux due to air injection (bubbles) (moles $\mathrm{m}^{-2} \mathrm{~s}^{-1}$ )

$F_{C} \quad$ gas flux due to complete trapping of bubbles (moles $\mathrm{m}^{-2} \mathrm{~s}^{-1}$ )

$F_{G E} \quad$ gas flux due to diffusive gas exchange (moles $\left.\mathrm{m}^{-2} \mathrm{~s}^{-1}\right)$

$F_{P} \quad$ gas flux due to partial trapping of bubbles $\left(\right.$ moles $\left.\mathrm{m}^{-2} \mathrm{~s}^{-1}\right)$

$F_{\text {TOT }}$ total air/sea gas exchange flux including contribution from diffusive gas exchange and air injection (moles $\left.\mathrm{m}^{-2} \mathrm{~s}^{-1}\right)$

$g \quad$ gravitational constant $=9.81 \mathrm{~m} \mathrm{~s}^{-2}$

$h_{b u b} \quad$ average dissolution depth of bubbles that are partially trapped (m)

$i \quad$ gas of interest

$K_{z} \quad$ vertical diffusivity parameter used in model $\left(\mathrm{m}^{2} \mathrm{~s}^{-1}\right)$

$n \quad$ exponent controlling the wind speed dependency of the diffusive gas exchange flux

$P_{i, a} \quad$ partial pressure of gas $i$ in the atmosphere $(\mathrm{Pa})$

$P_{i, b} \quad$ partial pressure of gas $i$ in the bubble $(\mathrm{Pa})$

$P_{i, w} \quad$ partial pressure of gas $i$ in the water $(\mathrm{Pa})$

Prod depth-dependent portion of the oxygen productivity profile used in the model

$P_{T O T}$ total $\mathrm{O}_{2}$ flux due to oxygen production and consumption used in model

$R \quad$ gas constant $=8.31 \mathrm{~J} \mathrm{~mol}^{-1} \mathrm{~K}^{-1}$

Sc Schmidt number (ratio of kinematic viscosity to molecular diffusivity)

slope slope calculated from the linearization of model parameter vs. observational metric

$T \quad$ temperature of water $(\mathrm{K})$

$t \quad$ time in model (year)

$u_{10} \quad$ wind speed at height of $10 \mathrm{~m}$ above surface $\left(\mathrm{m} \mathrm{s}^{-1}\right)$

$v_{a} \quad$ air entrainment velocity $=0.01 \mathrm{~m} \mathrm{~s}^{-1}$

$X_{i} \quad$ mole fraction of gas $i$ in dry air

$Z \quad$ parameter used in model for depth over which the total heat flux offset (sum of Ekman and NCEP imbalance compensation terms) is distributed (m)

$z$ depth in model used in oxygen productivity $(\mathrm{m})$

scaling depth used in oxygen productivity (m)

$\Delta \quad$ saturation anomaly of gas (\%)

$\gamma_{A c} \quad$ tunable model parameter controlling the magnitude of the complete bubble trapping flux 
$\gamma_{A p} \quad$ tunable model parameter controlling the magnitude of the partial bubble trapping flux

$\gamma_{G} \quad$ tunable model parameter controlling the magnitude of the diffusive gas exchange flux

$\gamma_{P} \quad$ tunable model parameter controlling the magnitude of net biological $\mathrm{O}_{2}$ production $\left(\mathrm{mol} \mathrm{m}^{-2} \mathrm{y}^{-1}\right)$

$\rho \quad$ density of water $\left(\mathrm{kg} \mathrm{m}^{-3}\right)$

$\sigma_{\text {param }}$ uncertainty in the model parameter, equals constraint on model parameter

$\sigma_{\text {metric }}$ estimated uncertainty in observational metric

\section{REFERENCES}

Anderson, L. A. and J. L. Sarmiento. 1994. Redfield ratios of remineralization determined by nutrient data-analysis. Global Biogeochem. Cycles, 8, 65-80.

Broecker, W. S. and T. H. Peng. 1974. Gas-exchange rates between air and sea. Tellus, 26, 21-35.

Doney, S. C. 1996. A synoptic atmospheric surface forcing data set and physical upper ocean model for the U.S. JGOFS Bermuda Atlantic Time-series Study Site. J. Geophys. Res., 101, 2561525634.

Fuchs, G., W. Roether and P. Schlosser. 1987. Excess 3He in the ocean surface layer. J. Geophys. Res., 92, 6559-6568.

Graham, A., D. K. Woolf and A. J. Hall. 2004. Aeration due to breaking waves. Part I: Bubble populations. J. Phys. Oceanogr., 34, 989-1007.

Gruber, N., C. D. Keeling and T. F. Stocker. 1998. Carbon-13 constraints on the seasonal inorganic carbon budget at the BATS site in the northwestern Sargasso Sea. Deep-Sea Res. I, 45, 673-717.

Hamme, R. C. and S. Emerson. 2004. The solubility of neon, nitrogen and argon in distilled water and seawater. Deep-Sea Res. I, 51, 1517-1528.

Hood, E. M. 1998. Characterization of air-sea gas exchange processes and dissolved gas/ice interactions using noble gases. Ph.D. Thesis MIT/WHOI, WHOI 98-01.

Jähne, B., G. Heinz and W. Dietrich. 1987. Measurement of the diffusion coefficients of sparingly soluble gases in water. J. Geophys. Res., 92, 10767-10776.

Jenkins, W. J. 1980. Tritium and He-3 in the Sargasso Sea. J. Mar. Res., 38, 533-569.

- 1988. The use of anthropogenic tritium and He-3 to study sub-tropical gyre ventilation and circulation. Philosophical Transactions of the Royal Society of London Series A-Mathematical Physical and Engineering Sciences, 325, 43-61.

Jenkins, W. J. and S. C. Doney. 2003. The subtropical nutrient spiral. Global Biogeochem. Cycles, 17, 1110, doi:10.1029/2003GB002085.

Jenkins, W. J. and J. C. Goldman. 1985. Seasonal oxygen cycling and primary production in the Sargasso Sea. J. Mar. Res., 43, 465-491.

Keeling, R. F. 1993. On the role of large bubbles in air-sea gas-exchange and supersaturation in the ocean. J. Mar. Res., 51, 237-271.

Kistler, R., E. Kalnay, W. Collins, S. Saha, G. White, J. Woollen, M. Chelliah, W. Ebisuzaki, M. Kanamitsu, V. Kousky, H. van den Dool, R. Jenne and M. Fiorino. 2001. The NCEP-NCAR 50-year reanalysis: Monthly means CD-ROM and documentation. Bulletin of the American Meteorological Society, 82, 247-267.

Levich, V. G. 1962. Physiochemical Hydrodynamics, Prentice-Hall, 700 pp.

Liss, P. S. and L. Merlivat. 1986. Air-Sea gas exchange rates: Introduction and synthesis, in The Role of Air-Sea Gas Exchange in Geochemical Cycling, P. Buat-Menard, ed., D. Reidel, 113-127. 
Lott, D. E. 2001. Improvements in noble gas separation methodology: a nude cryogenic trap. Geochem. Geophys. Geosys., 2, 10.129/2001GC000202.

Lott, D. E. and W. J. Jenkins. 1998. Advances in analysis and shipboard processing of tritium and helium samples. International WOCE Newsletter, 30, 27-30.

Michaels, A. F. and A. H. Knap. 1996. Overview of the U.S. JGOFS Bermuda Atlantic Time-series Study and the Hydrostation S program. Deep-Sea Res. II, 43, 157-198.

Monahan, E. C. and T. Torgersen. 1990. Enhancement of air-sea gas exchange by oceanic whitecapping, in Air-Water Mass Transfer, Second International Symposium on Gas Transfer at Water Surfaces, 608-617.

Musgrave, D. L., J. Chou and W. J. Jenkins. 1988. Application of a model of upper-ocean physics for studying seasonal cycles of oxygen. J. Geophys. Res.-Oceans, 93, 15679-15700.

Nightingale, P. D., G. Malin, C. S. Law, A. Watson, P. S. Liss, M. I. Liddicoat, J. Boutin and R. Upstill-Goddard. 2000. In situ evaluation of air-sea gas exchange parameterizations novel conservative and volatile tracers. Global Biogeochem. Cycles, 14, 373-387.

Peng, T. H., W. S. Broecker, G. G. Mathieu, Y. H. Li and A. E. Bainbridge. 1979. Radon evasion rates in the Atlantic and Pacific oceans as determined during the GEOSECS program. J. Geophys. Res., 84, 2471-2486.

Price, J. F., R. A. Weller and R. Pinkel. 1986. Diurnal cycling - observations and models of the upper ocean response to diurnal heating, cooling, and wind mixing. J. Geophys. Res.-Oceans, 91, 8411-8427.

Schroeder, E. and H. Stommel. 1969. How representative is the series of PANULIRUS stations of monthly mean conditions off Bermuda? Prog. Oceanogr., 5, 31-40.

Spitzer, W. S. 1989. Rates of vertical mixing, gas exchange and net production: Estimates from seasonal gas cycles in the upper ocean near Bermuda. Ph.D. Thesis MIT/WHOI, WHOI-89-30.

Spitzer, W. S. and W. J. Jenkins. 1989. Rates of vertical mixing, gas-exchange and new production estimates from seasonal gas cycles in the upper ocean near Bermuda. J. Mar. Res., 47, 169-196.

Wanninkhof, R. 1992. Relationship between wind speed and gas exchange over the ocean. J. Geophys. Res., 97, 7373-7382.

Wanninkhof, R. and W. R. McGillis. 1999. A cubic relationship between air-sea $\mathrm{CO}_{2}$ exchange and wind speed. Geophys. Res. Lett., 26, 1889-1892.

Watson, A. J., R. C. Upstill-Goddard and P. S. Liss. 1991. Air-sea gas exchange in rough and stormy seas measured by a dual-tracer technique. Nature, 349, 145-147.

Weiss, R. F. 1970. The solubility of nitrogen, oxygen and argon in water and seawater. Deep-Sea Res., 17, 721-735.

1971. Solubility of helium and neon in water and seawater. J. Chem. Engineer. Data, 16, 235-241.

Weiss, R. F. and T. K. Kyser. 1978. Solubility of krypton in water and seawater. J. Chem. Engineer. Data, 23, 69-72.

Wood, D. and R. Caputi. 1966. Solubilities of $\mathrm{Kr}$ and $\mathrm{Xe}$ in fresh and sea water. U.S. Naval Radiological Defense Laboratory, 14.

Woolf, D. K. 1993. Bubbles and the air-sea transfer velocity of gases. Atmosphere-Ocean, 31, 517-540.

Received: 11 April, 2005; revised: 13 January, 2006. 